\title{
Crown ether modulation enables over $23 \%$ efficient formamidinium-based perovskite solar cells
}

Tzu-Sen $\mathrm{Su}^{1,6, \#}$, Felix Thomas Eickemeyer ${ }^{1,5, \# \text {, Michael A. Hope }}{ }^{2, \#}$, Farzaneh Jahanbakhshi ${ }^{3, \#}$, Marko Mladenovic ${ }^{3}$, Jun $\mathrm{Li}^{1}$, Zhiwen Zhou ${ }^{1}$, Aditya Mishra ${ }^{2}$, Jun-Ho Yum ${ }^{4}$, Dan Ren ${ }^{1}$, Anurag Krishna ${ }^{5}$, Olivier Ouellette ${ }^{1}$, Tzu-Chien Wei ${ }^{6}$, Hua Zhou ${ }^{7}$, Hsing-Hsiang Huang ${ }^{8}$, Mounir Driss Mensi ${ }^{9}$, Kevin Sivula $^{4}$, Shaik M. Zakeeruddin ${ }^{1}$, Anders Hagfeldt ${ }^{5}$, Ursula Rothlisberger ${ }^{3}$, Lyndon Emsley ${ }^{2}$, Hong Zhang $^{1, *}$, Michael Grätzel ${ }^{1, *}$

${ }^{1}$ Laboratory of Photonics and Interfaces, École Polytechnique Fédérale de Lausanne, Lausanne 1015, Switzerland.

${ }^{2}$ Laboratory of Magnetic Resonance, Institute of Chemical Sciences and Engineering, École Polytechnique Fédérale de Lausanne, Lausanne 1015, Switzerland.

${ }^{3}$ Laboratory of Computational Chemistry and Biochemistry, École Polytechnique Fédérale de Lausanne, Lausanne 1015, Switzerland.

${ }^{4}$ Laboratory of Molecular Engineering of Optoelectronic Nanomaterials, Institute of Chemical Sciences and Engineering, École Polytechnique Fédérale de Lausanne (EPFL), Lausanne 1015, Switzerland.

${ }^{5}$ Laboratory of Photomolecular Science, Institute of Chemical Sciences and Engineering, École Polytechnique Fédérale de Lausanne, Lausanne 1015, Switzerland.

${ }^{6}$ Department of Chemical Engineering, National Tsing Hua University, Hsinchu 300, Taiwan.

${ }^{7}$ Advanced Photon Source, Argonne National Laboratory, Lemont, Illinois 60439, United States.

${ }^{8}$ Materials Science Division and Center for Molecular Engineering, Argonne National Laboratory, Lemont, Illinois 60439, United States.

${ }^{9}$ Institute of Chemical Sciences and Engineering, École Polytechnique Fédérale de Lausanne, Valais Wallis, CH-1951 Sion, Switzerland. 


\begin{abstract}
The use of tailored molecular modulators to reduce the defect density at the surface and grain boundaries of perovskite materials has been demonstrated to be an effective approach to enhance the photovoltaic performance and device stability of perovskite solar cells. Herein, we report a host-guest strategy to modulate perovskite films, affording passivation of undercoordinated surface metal or organic cation defects via crown ether complexation. This molecular interaction has been elucidated by solid-state nuclear magnetic resonance and density functional theory calculations. The crown ether induces the self-assembly of supramolecular host-guest complexes on the top of the perovskite film, which reduces the concentration of surface electronic defects and suppresses nonradiative recombination by $40 \%$, as well as minimizing moisture permeation. As a result, we achieved significantly improved photovoltaic performance with power conversion efficiencies exceeding $23 \%$, accompanied by enhanced stability under ambient and operational conditions. The optoelectronic performance has been analyzed quantitatively by a combination of photoluminescence, photoluminescence quantum yield, and time-resolved photoluminescence measurements. This work opens a new avenue to improve the performance and stability of perovskite-based optoelectronic devices through supramolecular chemistry.
\end{abstract}




\section{INTRODUCTION}

Metal halide perovskites have attracted wide attention mainly because of their excellent opto-electronic properties. ${ }^{1-3}$ The power conversion efficiency (PCE) of solution processed perovskite solar cell (PSCs) has increased from an initial $3.8 \%$ to a certified $25.2 \%$, which renders them promising candidates for next-generation photovoltaic devices. However, numerous crystal defects including anion vacancies and undercoordinated lead cations, formed mostly at the surface and grain boundaries of the perovskite layer, ${ }^{4-5}$ impair the stability and performance of PSCs.$^{6-7}$ The vacancy defects provide a pathway for ion migration, which results in fast degradation of PSCs under operational conditions. ${ }^{8}$ Furthermore, several studies have indicated that surface defects and grain boundaries can serve as carrier recombination sites and thus result in PCE loss. ${ }^{9-10}$ Some organic molecules are capable of passivating the defect sites at the surface and grain boundaries via coordinative bonding or ionic bonding. ${ }^{11}$ For example, a tailored organohalide molecule (i.e.., 1,2,4,5-tetrafluoro-3,6-diiodobenzene ${ }^{12}$ ) has been proposed to coordinate with under-coordinated halide anions on the perovskite surface, passivating them and thus significantly increasing the PSC performances. The uncoordinated metal cations on the surface of perovskite films can be passivated by Lewis bases containing lone pairs of electrons on oxygen, nitrogen, or sulfur (e.g., pyridine, ${ }^{10}$ thiophene, ${ }^{10}$ benzoquinone ${ }^{13}$ ). In addition, some electronic trap states can be passivated by Lewis acid molecules, such as bis- phenyl-C61-butyric acid methyl ester (PCBM) mixed isomers, which accept electrons from the Lewis base type defects on the perovskite surface. ${ }^{14}$ The surface charged sites can also be neutralized by molecular or atomic ions, such as phenethylammonium cations ${ }^{15}$ or chloride anions; ${ }^{16}$ in some cases both the cation and anion have been shown to be active (e.g., choline chloride ${ }^{17}$ ). Based on these previous results, modulators are an effective strategy for perovskite defect passivation; nevertheless, designing new and more effective modulators is highly required to further improve the efficiency of PSCs toward their efficiency limit $(\sim 31 \%),{ }^{18}$ as well as to enhance their operational stability.

Crown ethers are well-known cyclic molecules containing a ring with ether groups. This results in a highly electronegative cavity, which can selectively complex different metal or organic cations, whereby the selectivity is based on the size of the ring structure. ${ }^{19}$ As a result, crown ethers are widely used as complex reagents and phase transfer catalysts in synthesis. ${ }^{20}$

Herein, we report a host-guest strategy to modulate perovskite films, affording passivation of undercoordinated surface metal or organic cation defects via crown ether complexation. This strong interaction has been elucidated by solid-state nuclear magnetic resonance spectroscopy (NMR), attenuated total reflection Fourier-transform infrared spectroscopy (ATR-FTIR), X-ray photoelectron spectroscopy (XPS), and density functional theory (DFT) calculations. We show that the crown ether surface modulation reduces the trap state density at the interface and grain boundaries of perovskite film, thus greatly suppressing non-radiative recombination. As a result, the crown ether modulated PSCs exhibit improved PCE exceeding 23\%, accompanied by enhanced stability under ambient and operational conditions.

\section{RESULTS AND DISCUSSION}

Double cation, double halide, $\mathrm{FA}_{0.97} \mathrm{MA}_{0.03} \mathrm{PbI}_{2.97} \mathrm{Br}_{0.03}$ perovskite layers $\left(\mathrm{FA}^{+}=\right.$formamidinium $=$ 
$\mathrm{CH}\left(\mathrm{NH}_{2}\right)_{2}{ }^{+} ; \mathrm{MA}^{+}=$methylammonium $\left.=\mathrm{CH}_{3} \mathrm{NH}_{3}{ }^{+}\right)$were prepared and deposited onto the mesoporous $\mathrm{TiO}_{2}\left(\mathrm{mp}-\mathrm{TiO}_{2}\right.$ ) layer by a one-step method using an antisolvent (see Methods). In a preliminary study, two crown ethers were studied, with similar cavities but with or without benzannulation (18-crown-6 ether, 18C6; dibenzo-18-crown-6, DB18C6). The devices with DB18C6 treatment were found to exhibit better photovoltaic performance than those with 18C6 (Fig. S1 and Table S1). Moreover, DB18C6 has a higher reported hydrophobicity than $18 \mathrm{C} 6,{ }^{21}$ which might enhance the moisture tolerance of the perovskite film in air. Based on the prospect of increased cell efficiency and hydrophobicity, benzannulated crown ethers were selected for the second round of screening: DB18C6; dibenzo-21-crown-7, DB21C7; dibenzo-24-crown-8, DB24C8; and dibenzo-30-crown-10, DB30C10 (Fig. 1a). The ring size of the crown ether was optimized with respect to the overall photovoltaic performance. As shown in Fig. S2 and Table $\mathrm{S} 2$, the open circuit voltage $\left(V_{\mathrm{OC}}\right)$ and power conversion efficiency (PCE) of benzannulated crown ether modulated PSCs significantly improved with increasing the size of the macrocycle from DB18C6 to DB24C8. Further increasing the size of the macrocycle (i.e., DB30C10) leads to a reduction of $V_{\mathrm{OC}}$. DB24C8 modulated PSCs showed the best overall photovoltaic performance, and we therefore used DB24C8 for further detailed studies in this manuscript.

\section{Morphology and structural characterization}

The morphology of the perovskite surface was analysed for control and crown ether-treated perovskite films by scanning electron microscopy (SEM; Fig. 1b,c). Both control and treated perovskite films are uniform and highly crystalline with similar compact textures and grain sizes in the range of hundreds of nanometers. Excess $\mathrm{PbI}_{2}$ (located at the grain boundaries ${ }^{7}$ ) disappeared upon crown ether treatment of the films. The structural properties of the perovskite films were further analyzed by grazing incidence wide-angle X-ray scattering (GIWAXS; Fig. 1d) at two different angles of incidences, i.e., $0.1^{\circ}$ (more surface sensitive) and $0.3^{\circ}$ (more bulk sensitive). Both the control and treated perovskite films show identical Bragg reflections and a preferred orientation for the perovskite phase. Compared to the control films, two additional low-q signals $\left(\sim 0.39\right.$ and $\left.\sim 0.73 \AA^{-1}\right)$ appear in the treated films; the relative Bragg peak intensities decrease with increasing penetration depth (Fig. 1e), implying that the new species are located predominantly at the surface of perovskite film, consistent with the new species observed in the SEM image (Fig. 1b). These new species could be formed by the host-guest complexation of the crown ether with cations on the perovskite surface. ${ }^{22}$

The effects of crown ether treatment on the perovskite surface were further investigated by ATR-FTIR and XPS. The FTIR spectrum of pristine crown ether (DB24C8) powder reveals two characteristic peaks of the C-O stretching vibration at $\sim 1121 \mathrm{~cm}^{-1}$ and $\sim 1219 \mathrm{~cm}^{-1}$ (Fig. 1f), while the control perovskite film does not exhibit these two peaks. For the crown ether treated perovskite film, these $\mathrm{C}-\mathrm{O}$ stretching vibrations are still present, but slightly shifted to $1131 \mathrm{~cm}^{-1}$ and $1211 \mathrm{~cm}^{-1}$, respectively, indicating an interaction between the functional groups of the crown ether (i.e., the oxygen atoms in the ring) and the perovskite film. A change in the XPS spectra of the perovskite is also observed upon crown ether treatment (Fig. 1g, h). A new peak in the $\mathrm{O} 1 \mathrm{~s}$ level range at $533.0 \mathrm{eV}$ (Fig. 1g) that is associated with the $\mathrm{C}-\mathrm{O}$ bond suggests 
that the crown ether is adsorbed on the surface of the treated perovskite film. The XPS spectrum of the control sample in the $\mathrm{Pb} 4 f$ level range (Fig. 1h) reveals two main peaks associated with $\mathrm{Pb} 4 f_{7 / 2}$ and $\mathrm{Pb}$ $4 f_{5 / 2}$ at 138.3 and $143.1 \mathrm{eV}$, respectively, attributed to $\mathrm{Pb}-\mathrm{I}$ species, along with two smaller peaks located at 136.4 and $141.4 \mathrm{eV}$ that arise from the presence of metallic $\mathrm{Pb}^{7}$ The metallic $\mathrm{Pb}$ peak vanishes in the crown ether treated film, which suggests that crown ether treatment protects against the degradation processes that lead to the formation of metallic $\mathrm{Pb}$. Meanwhile, after crown ether treatment, the two major peaks associated with $\mathrm{Pb} 4 f_{7 / 2}$ and $\mathrm{Pb} 4 f_{5 / 2}$ shift to lower energies of $138.1 \mathrm{eV}$ and $142.8 \mathrm{eV}$, respectively. Taken together, these results suggest that the crown ether is not just adsorbed physically but reacts with the surface of the perovskite film, presumably through coordinating interactions between the oxygen atoms of the macrocycle and undercoordinated cations.

a

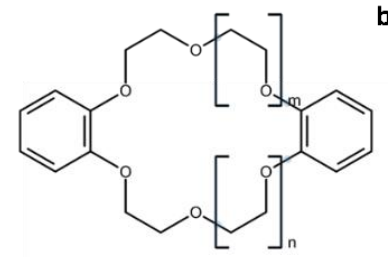

1. $m=1 ; n=1$ Dibenzo-18-crown-6

2. $m=1 ; n=2$ Dibenzo-21-crown-7

3. $m=2 ; n=2$ Dibenzo-24-crown-8
4. $m=3 ; n=3$ Dibenzo-30-crown-10
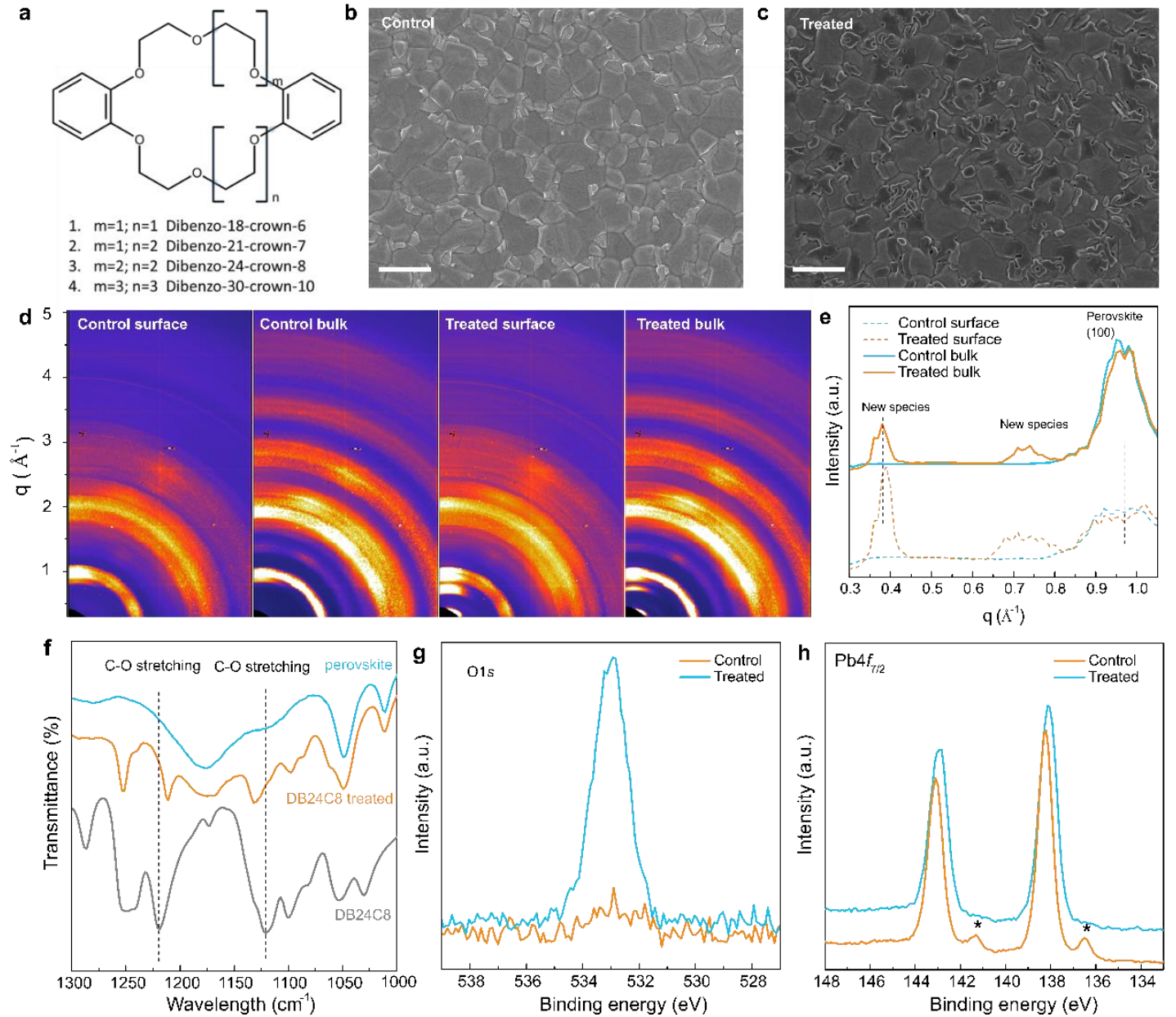

Figure 1. Morphology and structural characterizations. a, Molecular structure of benzannulated crown ethers used in this study. Top-view SEM images of $\mathbf{b}$, control and $\mathbf{c}$, crown ether-treated perovskite films. The scale bar represents $2 \mu \mathrm{m}$. d, GIWAXS two-dimensional reciprocal space maps of control sample and treated sample at incidence angles of $\alpha_{\mathrm{i}}=0.1^{\circ}$, to probe the surface of the material; and $\alpha_{i}=0.30^{\circ}$, to probe the bulk material. e, Radially integrated intensity of GIWAXS data in $\mathrm{b}$ and c. f, Attenuated total reflection Fourier transform infrared (ATR-FTIR) spectra of pristine perovskite film, crown ether treated perovskite film, and crown ether (DB24C8) powder. g-h, X-ray photoelectron spectroscopy (XPS) core-level spectra of pristine perovskite film and crown ether treated perovskite film for O $1 s(\mathrm{~g})$ and $\mathrm{Pb} 4 f(\mathrm{~h})$. The astrisk $(*)$ indicates metallic $\mathrm{Pb}$ species. 


\section{Mechanistic study of crown ether modulation}

Further insight into the mechanism of crown ether modulation was gained by studying bulk mechanosynthesised samples ${ }^{23}$ with solid state NMR. NMR, as an element-specific probe of local structure, is a powerful tool to determine dopant incorporation and surface modification in perovskite systems. ${ }^{24-27}$ In particular, ${ }^{13} \mathrm{C} \mathrm{NMR}^{28}$ and ${ }^{207} \mathrm{~Pb} \mathrm{NMR}^{29-30}$ are sensitive to the local environment of the organic and inorganic cations, respectively, while ${ }^{1} \mathrm{H}-{ }^{1} \mathrm{H}$ spin diffusion experiments can be used to demonstrate atomic-scale proximity (up to $\sim 10 \AA$ ) ${ }^{26}$.

To investigate the possibility of complexation of $\mathrm{FA}^{+}$and $\mathrm{Pb}^{2+}$ by DB24C8, bulk samples of 1:1 mole ratio $\mathrm{PbI}_{2}: \mathrm{DB} 24 \mathrm{C} 8$ and FAI:DB24C8 were investigated. For DB24C8- $\mathrm{PbI}_{2}$, there is no change observed in either the $\mathrm{PbI}_{2}$ structure as measured by the ${ }^{207} \mathrm{~Pb}$ spectrum (Fig 2a), nor in the DB24C8 as probed by the ${ }^{13} \mathrm{C}$ spectrum (Fig 2b), and no additional reflections are seen in the XRD pattern (Fig S3). This shows that the crown ether cannot form a complex with $\mathrm{PbI}_{2}$ under these conditions, most likely due to the high lattice energy of the $\mathrm{PbI}_{2}$ salt. In contrast, for $\mathrm{DB} 24 \mathrm{C} 8-\mathrm{FAI}$, clear changes are seen for the ${ }^{13} \mathrm{C}$ signals of the crown ether (Fig $2 \mathrm{~b}$ ), most notably an upfield shift of the phenyl-ether environment from $158.3 \mathrm{ppm}$ to $156.9 \mathrm{ppm}$. The $\mathrm{FA}^{+}$signal also shifts from $\delta{ }^{13} \mathrm{C}=164.8 \mathrm{ppm}$ for FAI to $\sim 168 \mathrm{ppm}$ in DB24C8-FAI, concomitantly with a shift in the $\mathrm{FA}^{+}{ }^{1} \mathrm{H}$ signal from $\delta{ }^{1} \mathrm{H} \approx 8.1 \mathrm{ppm}$ in FAI to 8.5-9.0 ppm in DB24C8-

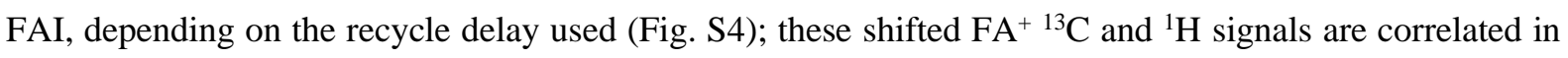
the ${ }^{1} \mathrm{H} \rightarrow{ }^{13} \mathrm{C}$ HETCOR spectrum (Fig. S5). Finally, atomic scale proximity between the crown ether and $\mathrm{FA}^{+}$is demonstrated by cross peaks in the ${ }^{1} \mathrm{H}-{ }^{1} \mathrm{H}$ spin diffusion spectrum (Fig S6). Together, these results indicate the formation of a DB24C8-FAI complex. In the XRD pattern (Fig S3), additional low angle reflections are seen including a low angle reflection at $2 \theta=7.1\left(\mathrm{q}=0.51 \AA^{-1}\right)$, supporting the formation of a complex; notably, this reflection was not observed for the treated films, indicating that the major species formed there is not the same as this DB24C8-FAI complex, although polymorphism cannot be ruled out.

Subsequently, the interaction between $\mathrm{DB} 24 \mathrm{C} 8$ and bulk $\mathrm{FAPbI}_{3}$ perovskite was studied. $\alpha-\mathrm{FAPbI}_{3}$ was prepared by ball-milling $\mathrm{PbI}_{2}$ and FAI and annealing at $150{ }^{\circ} \mathrm{C}$, before ball-milling with 10 at $\%$ DB24C8. Immediately, following ball-milling, the $\sim 1520 \mathrm{ppm}{ }^{207} \mathrm{~Pb}$ signal is indistinguishable from that of neat $\alpha-\mathrm{FAPbI}_{3}$ (Fig. 2a); however, after annealing at $95{ }^{\circ} \mathrm{C}$ for 15 minutes, a new signal is observed at $\sim 900$ ppm, which is ascribed to ${ }^{207} \mathrm{~Pb}$ environment interacting with the crown ether. We note that the relative ratio of the two signals is not quantitative due to fast transverse decay during the echo pulse sequence, and the high intensity of the new signal is most likely due to a longer $T_{2}$ relaxation constant (see Fig. S7). The ${ }^{13} \mathrm{C}$ spectrum (Fig. 2b) again shows significant changes to the crown ether signals, with an even greater upfield shift of the phenyl-ether environment to $155.9 \mathrm{ppm}$, confirming a reaction with the ether, as well as the appearance of a shifted $\mathrm{FA}^{+}$signal at $168.2 \mathrm{ppm}$, similar to DB24C8-FAI, in addition to the $\alpha-\mathrm{FAPbI}_{3}$ peak at $164.5 \mathrm{ppm}$. The atomic-scale proximity of the formamidinium and the crown ether is confirmed by ${ }^{1} \mathrm{H}-{ }^{1} \mathrm{H}$ spin diffusion (Fig 2d), where the correlation between the aliphatic signal of the crown ether $\left(\delta{ }^{1} \mathrm{H}=\right.$ $4.2 \mathrm{ppm}$ ) and the perovskite formamidinium signal $\left(\delta^{1} \mathrm{H} \approx 7.7 \mathrm{ppm}\right)$ can be distinguished from correlation with the aromatic ether signal $\left(\delta{ }^{1} \mathrm{H}=6.5 \mathrm{ppm}\right)$. A minor signal can also be observed at $\delta{ }^{1} \mathrm{H}=9.3 \mathrm{ppm}$, 
assigned to $\mathrm{FA}^{+}$interacting with the ether (denoted FA*), as also observed for DB24C8-FAI (Fig S3); this signal also correlates with the DB24C8 crown ether, which can most easily be seen by taking the $4.1 \mathrm{ppm}$ row from the 2D (Fig S5). The new ${ }^{207} \mathrm{~Pb}$ environment correlates with the ether and modified $\mathrm{FA}^{+}{ }^{1} \mathrm{H}$ signals between $3-10 \mathrm{ppm}$ in the ${ }^{207} \mathrm{~Pb} \rightarrow{ }^{1} \mathrm{H}$ HETCOR spectrum (Fig. 2c), whereas the $\alpha-\mathrm{FAPbI}_{3}{ }^{207} \mathrm{~Pb}$ signal correlates only with the major $\mathrm{FA}^{+}$signal at $\delta{ }^{1} \mathrm{H}=7.5 \mathrm{ppm}$. The HETCOR spectrum was recorded at $113 \mathrm{~K}$ since only the $\alpha-\mathrm{FAPbI}_{3}$ correlation could be observed at room temperature, presumably due to dynamics of the ether; consequently, all the ${ }^{207} \mathrm{~Pb}$ signals are observed at lower frequencies than at room temperature due to the strong temperature dependence of ${ }^{207} \mathrm{~Pb}$ chemical shifts. ${ }^{30} \mathrm{~A}$ minor component of $\delta$ - $\mathrm{FAPbI}_{3}$ can also be observed since its ${ }^{207} \mathrm{~Pb}$ signal is significantly sharper than $\alpha-\mathrm{FAPbI}_{3}$ at low temperature (Fig. S8). Taken together, the NMR results clearly indicate the formation of a mixed perovskite-DB24C8 phase, with atomic proximity between $\mathrm{FA}, \mathrm{Pb}$, and the crown ether. The formation of a new phase is also supported by XRD characterization (Fig S3), with additional major low-angle peaks at $2 \theta=5.6^{\circ}$ and $9.3^{\circ}\left(\mathrm{q}=0.40\right.$ and $\left.0.66 \AA^{-1}\right)$, although the low-angle reflections observed for the treated perovskite film at $2 \theta=5.3^{\circ}$ and $10.5^{\circ}\left(\mathrm{q}=0.38,0.75 \AA^{-1}\right)$, can also be observed, albeit with lower intensity and wider peak-width. This suggests that similar species are formed in both cases, perhaps with some polymorphism.
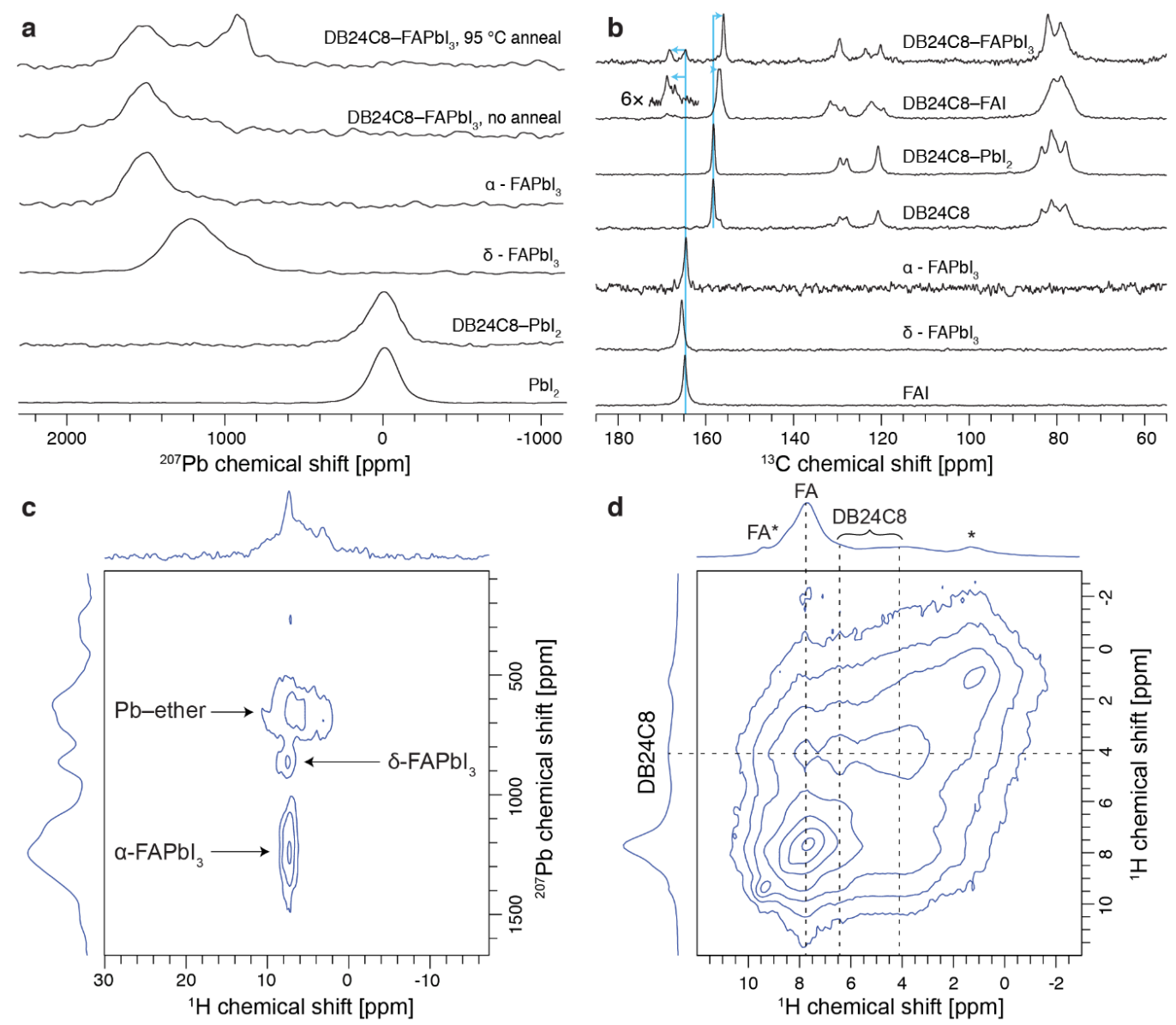

Figure 2. Atomic-level insights into the crown ether modulation by NMR. a, ${ }^{207} \mathrm{~Pb}$ echo and $\mathbf{b},{ }^{1} \mathrm{H} \rightarrow{ }^{13} \mathrm{C} \mathrm{CP}$ NMR spectra of $\mathrm{FAI}, \mathrm{PbI}_{2}$ and $\mathrm{FAPbI}_{3}$, with and without ball-milling with $\mathrm{DB} 24 \mathrm{C} 8$ crown ether, recorded at 15 
kHz MAS. c, ${ }^{207} \mathrm{~Pb} \rightarrow{ }^{1} \mathrm{H}$ HETCOR spectrum ofDB24C $8-\mathrm{FAPbI}_{3}$ recorded at $113 \mathrm{~K}$ and $30 \mathrm{kHz}$ MAS. d, ${ }^{1} \mathrm{H}-{ }^{1} \mathrm{H}$ spin diffusion spectrum of DB24C8- $\mathrm{FAPbI}_{3}$, recorded at $40 \mathrm{kHz}$ MAS with a mixing time of $10 \mathrm{~ms}$. The asterisk indicates polypropylene from the ball-milling jar.

To shed further light on the crown ether modulation effects, density functional theory (DFT) calculations were performed on DB24C8-cation complexes and treated perovskite surfaces, using the procedure outlined in the methods section. The likelihood of formation of the two complexes DB24C8$\mathrm{FA}^{+}$and $\mathrm{DB} 24 \mathrm{C} 8-\mathrm{Pb}^{2+}$ was determined by calculating the corresponding complexation energies between the gas phase reactants and the complexes. According to the values reported in Table 1, the complexation energies of DB24C8-Pb ${ }^{2+}$ and DB24C8-24-FA ${ }^{+}$indicate that formation of both complexes is favorable, which suggests that undercoordinated surface $\mathrm{Pb}^{2+}$ or $\mathrm{FA}^{+}$ionic defects (e.g., FA cations that are in stoichiometric excess, present at interstitial lattice sites) could be passivated via crown ether complexation. However, the favorable formation of DB24C $8-\mathrm{Pb}^{2+}$ from the gas phase ion does not imply that the complex would form from crystalline $\mathrm{PbI}_{2}$, as discussed above.

Table 1. Complexation energies of DB24C8-Pb ${ }^{2+}$ and DB24C8-FA ${ }^{+}$.

\begin{tabular}{cc}
\hline Reaction & Complexation Energy $(\mathrm{eV})$ \\
\hline $\mathrm{DB} 24 \mathrm{C} 8-\mathrm{Pb}^{2+} \rightarrow \mathrm{DB} 24 \mathrm{C} 8+\mathrm{Pb}^{2+}$ & 8.79 \\
$\mathrm{DB} 24 \mathrm{C} 8-\mathrm{FA}^{+} \rightarrow \mathrm{DB} 24 \mathrm{C} 8+\mathrm{FA}^{+}$ & 1.79 \\
\hline
\end{tabular}

To reveal the changes in the interfacial properties of the crown ether-modulated perovskites, a comparative study was carried out on the electronic properties of pristine $\mathrm{FAPbI}_{3}, \mathrm{FAPbI}_{3}$ slabs containing an iodide vacancy, and $\mathrm{FAPbI}_{3}$ slabs containing an iodide vacancy in the presence of the crown ether (DB24C8), both for FAI-terminated (Fig. 3a,b) and $\mathrm{PbI}_{2}$-terminated (Fig. 3c,d) slabs of $\mathrm{FAPbI}_{3}$. We chose the iodide vacancy defect to study the effect of crown ether modulation because it has a lower formation energy than other defects (e.g. Pb vacancy and $\mathrm{Pb}-\mathrm{I}$ anti-site). ${ }^{31}$

As can be observed in Fig. 3e and Fig. S9, comparing the FAI-terminated pristine and iodide defected $\mathrm{FAPbI}_{3}$ slabs, the iodide vacancy introduces localized shallow states at the conduction band minimum of the perovskite. Upon crown ether treatment of $\mathrm{FAPbI}_{3}$, two sharp peaks belonging to the crown ether molecules at the surface of $\mathrm{FAPbI}_{3}$ are predicted close to the valence band edge of the perovskite. This suggests the possibility of crown ether acting as a barrier for the hole transport. It is however worth noting that the absolute positioning of the energy levels of the crown ether molecule is largely dependent on the electrostatic potential at the surface of the perovskite, and the dipole moment imposed by the configuration of the crown ether molecule. Comparing the untreated and treated $\mathrm{FAPbI}_{3}$, as highlighted in the inset of Fig. $3 \mathrm{f}$, a shift in the conduction band minimum takes place upon treatment with crown ether. This shift implies the presence of shallower trap states compared to the case of the untreated slab, which is beneficial for obtaining a higher $V_{\mathrm{OC}}$. In addition, strong hydrogen bonding between the $\mathrm{H}$ atom of the FA and the crown ether molecule is observed, which is also reflected in the high binding energy between the $\mathrm{FAPbI}_{3}$ slab and the crown of $3.03 \mathrm{eV}$. 
In the case of the $\mathrm{PbI}_{2}$-terminated $\mathrm{FAPbI}_{3}$ slab, low-density shallow states are now observed in the valence band, instead of the conduction band, upon creating the iodide vacancy, as shown in Fig. $3 \mathrm{f}$ and Fig. S10. Contrary to the FAI-terminated case, a rather insignificant shift in the valence band maximum takes place upon modulating the surface with the crown ether. Additionally, contrary to the FAI-terminated case, a relatively weak crown-slab binding is observed $(0.65 \mathrm{eV})$; the lower binding energy suggests that ether may preferentially bond to undercoordinated $\mathrm{FA}^{+}$cations at the surface, rather than $\mathrm{Pb}^{2+}$.

In summary, on the basis of the NMR and DFT calculation studies, we propose that the crown ether modulation mechanism is via the potential interaction sites illustrated in Fig. 3g. The crown ether would effectively passivate the uncoordinated $\mathrm{Pb}^{2+}$ defects and interact with $\mathrm{FA}^{+}$on the perovskite film to modulate its surface properties, the impact of which will be further investigated in the following.

a

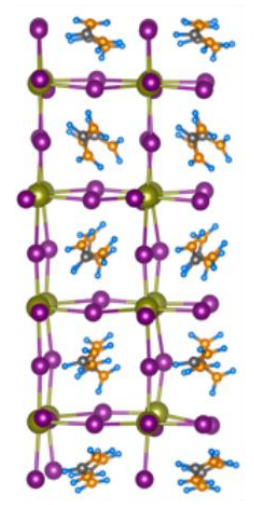

b
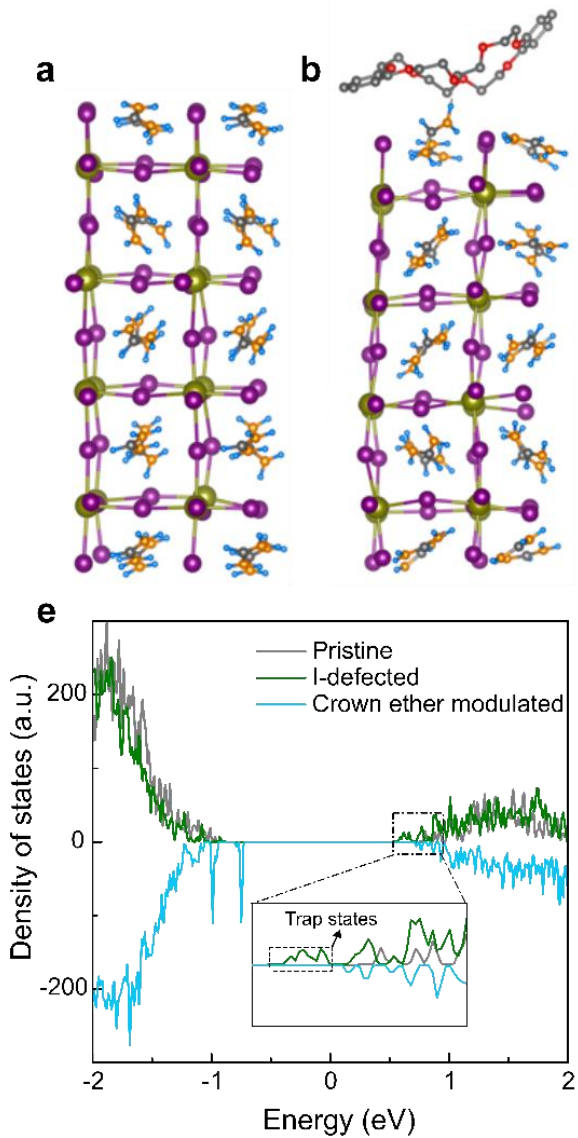

C

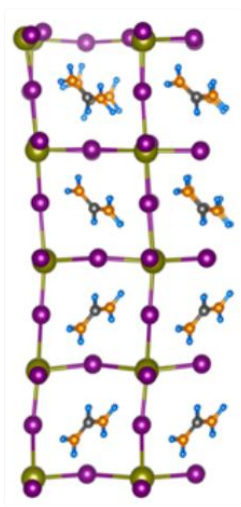

d
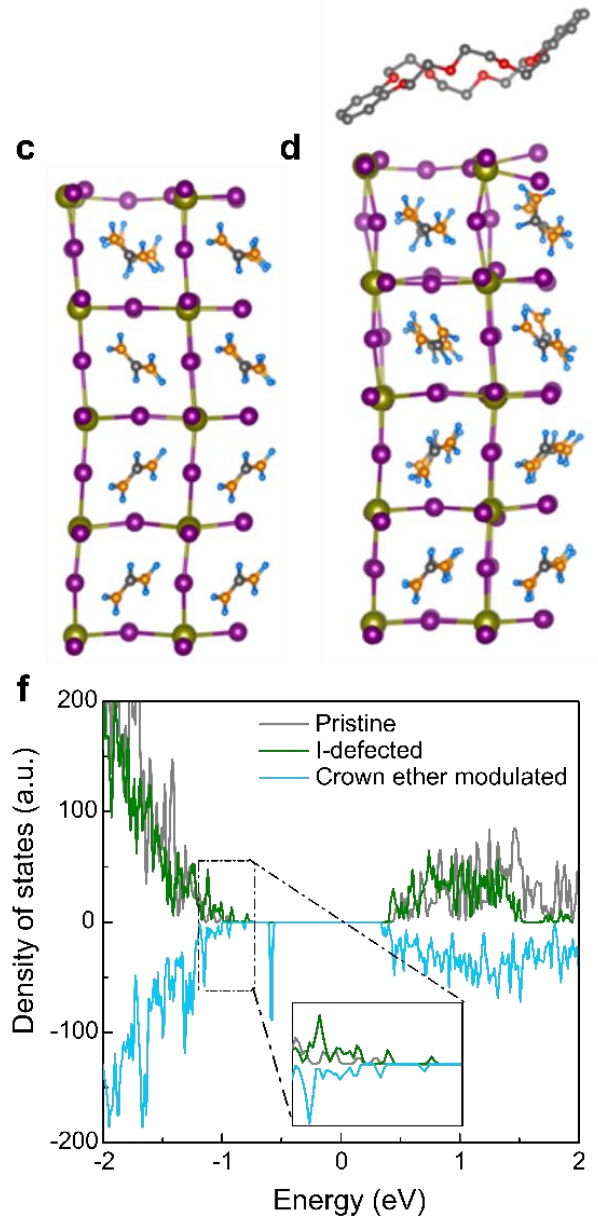

g

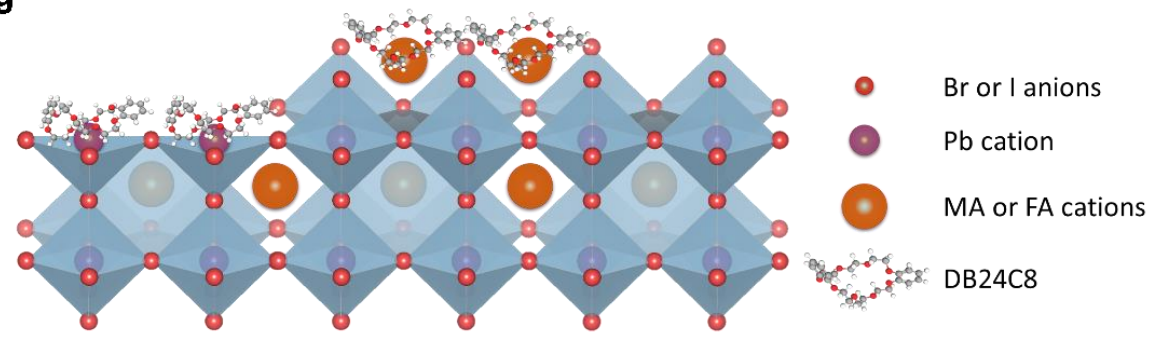

Figure 3. DFT calculations. a-b, FA-terminated slabs of $\mathrm{FAPbI}_{3}$ containing an iodide vacancy without (a) and 
with (b) crown ether-treatment, where $\mathrm{H}$ atoms of the crown are omitted for clarity. $\mathbf{c}$-d, $\mathrm{PbI}_{2}$-terminated slabs of $\mathrm{FAPbI}_{3}$ containing an iodide vacancy without (c) and with (d) crown ether-treatment. e-f, Density of states of the FA-terminated (e) and $\mathrm{PbI}_{2}$-terminated (f) slabs of pristine $\mathrm{FAPbI}_{3}, \mathrm{FAPbI}_{3}$ containing an iodide vacancy, and crown ether modulated $\mathrm{FAPbI}_{3}$ with an iodide vacancy. For readability purposes, the density of states has been mirrored for the modulated systems. g, Schematic illustration of possible crown ether modulation mechanism and potential interaction sites.

\section{Optical and electronic properties}

We further investigated the optical and electronic properties of perovskite film with and without crown ether modulation. As shown in Fig. 4a, the ultraviolet-visible (UV-Vis) absorption spectra show that the crown ether treatment did not change the optical properties (i.e., optical band-gap) of the perovskite films. Kelvin probe force microscopy (KPFM) of the crown ether treated perovskite film(Fig. 4b) revealed a higher $(+300 \mathrm{mV})$ and more homogeneous surface potential than that of the control film, which indicates a decrease in the number of grain boundaries upon crown ether treatment. The corresponding atomic force microscope (AFM) images are presented in Fig. S11. Ultraviolet photoelectron spectroscopy (UPS) results also show that the surface band structure of the perovskite has changed upon crown ether treatment (Fig. 4c), since the work function decreases by $0.44 \mathrm{eV}$ from 4.84 to $4.40 \mathrm{eV}$, as determined by a linear extrapolation of the secondary electron cutoff (Fig. 4c; left). The energy-level scheme for the perovskite film with and without passivation is presented in Fig. S12. These changes in the band structure of the perovskite surface are consistent with the shift of the surface potential probed by KPFM and DFT calculation results (Fig. 3e,f).

The decreased concentration of grain boundaries has been reported to reduce the trap state density and charge carrier recombination, ${ }^{32}$ which was further verified by cathodoluminescence $(\mathrm{CL})$ mapping of the perovskite deposited on thin $(1.1 \mathrm{~mm})$ FTO-coated glass substrates. Before CL characterization, the perovskite films were kept inside a vacuum chamber for a few hours in the dark, to avoid unintended light-induced degradation, and the CL mappings were recorded from regions of the sample that were previously unexposed, except when specifically indicated. The CL intensity for both samples was normalized to the peak value in the treated sample. As shown in Fig. 4d,e, the treated perovskite film showed brighter luminescence (higher CL intensity) than that of the control film, which indicates that the charge carrier recombination was suppressed via crown ether modulation. ${ }^{33}$ The non-emissive species in the treated sample are attributed to the crown ether complex. 

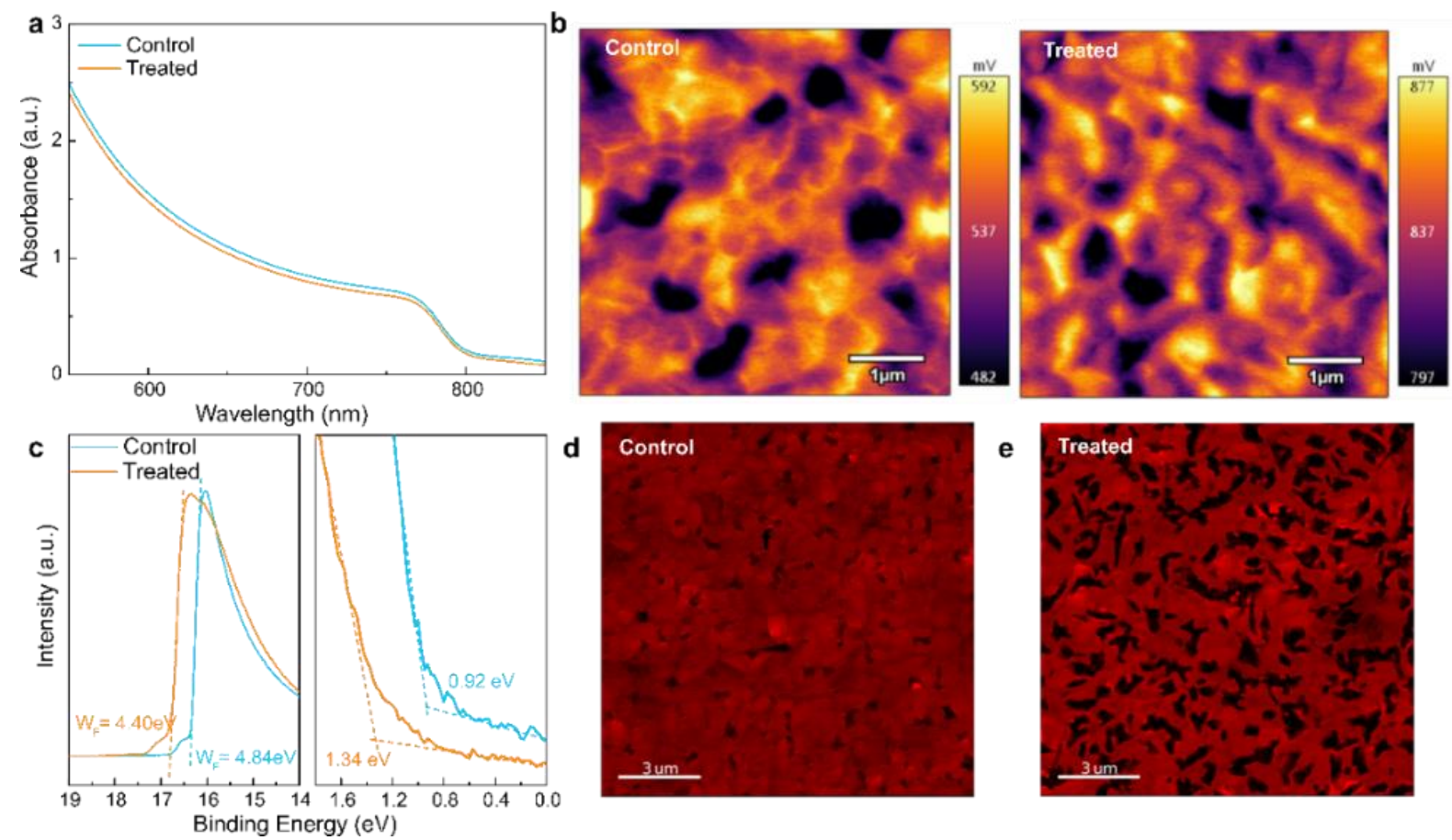

Figure 4. Effects of crown ether treatment on optical and electrical properties of perovskite films. a, UV-vis spectra, b, Kelvin probe force microscopy (KPFM) images, and c Ultraviolet photoelectron spectroscopy (UPS) spectra of secondary electron cut-off and valence band (VB) regions, for the control and treated perovskite films. d-e, Cathodoluminescence (CL) mapping of the control (d) and treated (e) perovskite films deposited on the FTO $(1.1 \mathrm{~mm})$ glass substrates. The spatial distribution of band edge emission intensity was normalized for both samples to the highest intensity in the treated sample, recorded from 800 to $850 \mathrm{~nm}$.

\section{Photovoltaic performance and stability}

Fig. 5a depicts a cross-sectional SEM image from a typical PSC with the structure: fluorine-doped tin oxide (FTO)/compact- $\mathrm{TiO}_{2}$ $\left(\mathrm{c}-\mathrm{TiO}_{2}\right) /$ mesoporous

$\mathrm{TiO}_{2}$ $\left(\mathrm{mp}-\mathrm{TiO}_{2}\right) /$ perovskite/2,2', 7,7'-Tetrakis[N,N-di(4-methoxyphenyl)amino]-9,9' -spirobifluorene (spiro-OMeTAD)/Au. The thicknesses of the perovskite absorbers are about $700 \mathrm{~nm}$, which is typical and reasonable for efficient PSCs. It is hard to observe the DB24C8 layer on the cross-sectional SEM image because it is too thin. The concentration of DB24C8 treatment solution was optimized with respect to the photovoltaic performance (see details in Fig. S13). Fig. 5b compares the photovoltaic metrics of the PSCs fabricated with optimized DB24C8 treatment and control PSCs. The average PCE values of the PSCs improved from $20.14 \pm 0.55 \%$ (control) to $21.51 \pm 0.61 \%$ for optimized DB24C8 treatment, mainly from an increase in $V_{\mathrm{OC}}$ (from $1.090 \pm 0.014 \mathrm{~V}$ to $1.142 \pm 0.009 \mathrm{~V}$ ), while exhibiting slightly higher short-circuit current density $\left(J_{\mathrm{SC}}\right)$ and fill factor $(\mathrm{FF})$ values. Fig. 5c shows the current density-voltage $(J-V)$ curves of champion devices (the front glass was coated with an antireflection film) with and without DB24C8 treatment. The photovoltaic parameters are summarized in Table 2. The control device measured with a reverse scan shows a typical PCE of $21.50 \%$ with a $J_{\mathrm{SC}}$ of $25.50 \mathrm{~mA} \mathrm{~cm}^{-2}$, a $V_{\mathrm{OC}}$ of $1.089 \mathrm{~V}$, and a FF of 0.773. Encouragingly, the treated device exhibited a $V_{\mathrm{OC}}$ of $1.154 \mathrm{~V}$, a $J_{\mathrm{SC}}$ of $25.80 \mathrm{~mA} \mathrm{~cm}^{-2}$, a FF of 0.795 , 
and a PCE of $23.70 \%$. The integrated current density derived from the external quantum efficiency (EQE; Fig. S14) matches the $J_{\mathrm{SC}}$ value obtained from the $J-V$ curve, excluding any significant spectral mismatch between our simulator and the AM1.5G solar source. We further ascertained these values by recording scan speed-independent maximum power point tracking (MPP) measurements (Fig. 5c, insert) corresponding to PCEs of $19.40 \%$ and $22.85 \%$ for the control and treated PSCs, respectively. In addition, we quantified the hysteresis effect across different devices by using a modified hysteresis index (HI) given by equation $(1)^{34}$ :

$$
H I=\frac{J_{\mathrm{R}}\left(0.8 V_{\mathrm{OC}}\right)-J_{\mathrm{F}}\left(0.8 V_{\mathrm{OC}}\right)}{J_{\mathrm{R}}\left(0.8 V_{\mathrm{OC}}\right)}
$$

where $J_{\mathrm{R}}\left(0.8 V_{\mathrm{OC}}\right)$ and $J_{\mathrm{F}}\left(0.8 V_{\mathrm{OC}}\right)$ represent the photocurrent density at $80 \%$ of the $V_{\mathrm{OC}}$ for the reverse scan (from open circuit to short circuit) and forward scan (from short circuit to open circuit), respectively. As shown in Fig. 5c and Table 2, the calculated HI of the DB24C8 treated device (0.05) is much smaller than that of the control device (0.165), which indicates that the hysteresis can be reduced by DB24C8 treatment. The reduced hysteresis by DB24C8 treatment may be attributed to the decrease in defect density at the interface between the perovskite and the hole transport layer (HTL) ${ }^{8}$.

In addition to the photovoltaic performance, we examined the stability of perovskite films and relevant devices. The composition change of pristine and DB24C8 treated perovskite films was investigated by XRD (Fig. 5d and Fig. S15). The much slower decomposition of $\mathrm{FAPbI}_{3}$ to $\mathrm{PbI}_{2}$ in the $\mathrm{DB} 24 \mathrm{C} 8$ treated perovskite films further demonstrates the better moisture resistance capability enabled by the crown ether modulation. Furthermore, the shelf-life time measurement for the DB24C8-treated devices shows slower average PCE drop than that of control devices after 23 days kept in the ambient conditions (Fig. 5e). The long-term operational stability of the PSCs was also probed by maximum power point (MPP) tracking on unencapsulated devices under constant simulated AM1.5 illumination $\left(100 \mathrm{~mW} \mathrm{~cm}{ }^{-2}\right)$. The DB24C8 treated devices maintain over $80 \%$ of their initial PCE after $300 \mathrm{~h}$ continuous tests, whereas the control devices degraded to $50 \%$ of their initial PCE after $50 \mathrm{~h}$ (Fig. $5 \mathrm{f}$ ). The enhanced ambient and operational stability can be attributed to the reduction of defects at the interface between the hole transport material and the perovskite absorber through crown ether treatment. 


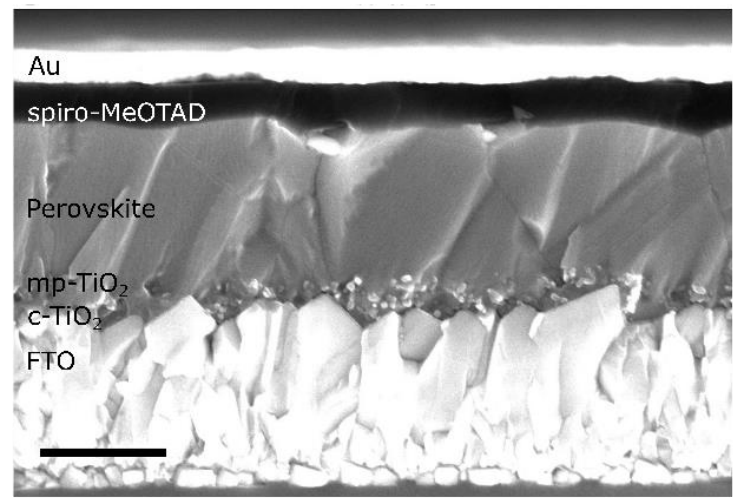

b
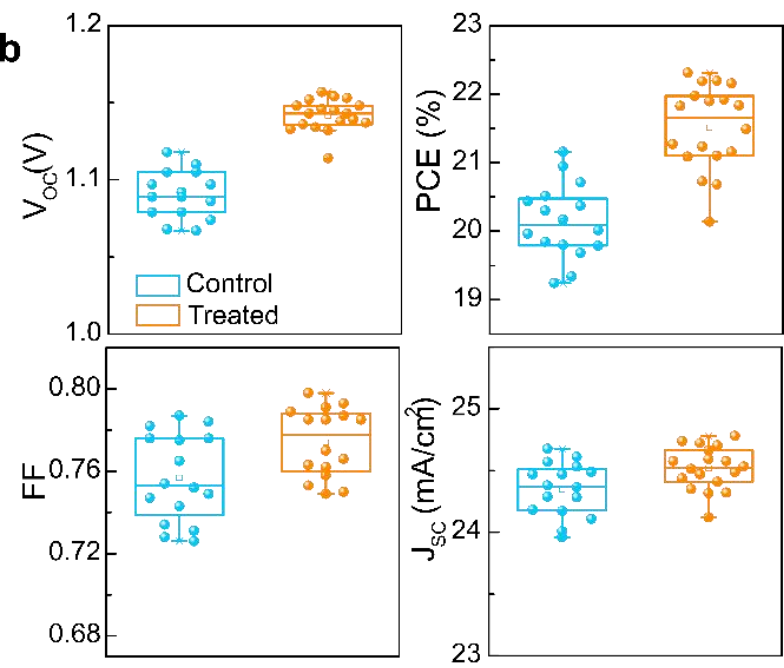
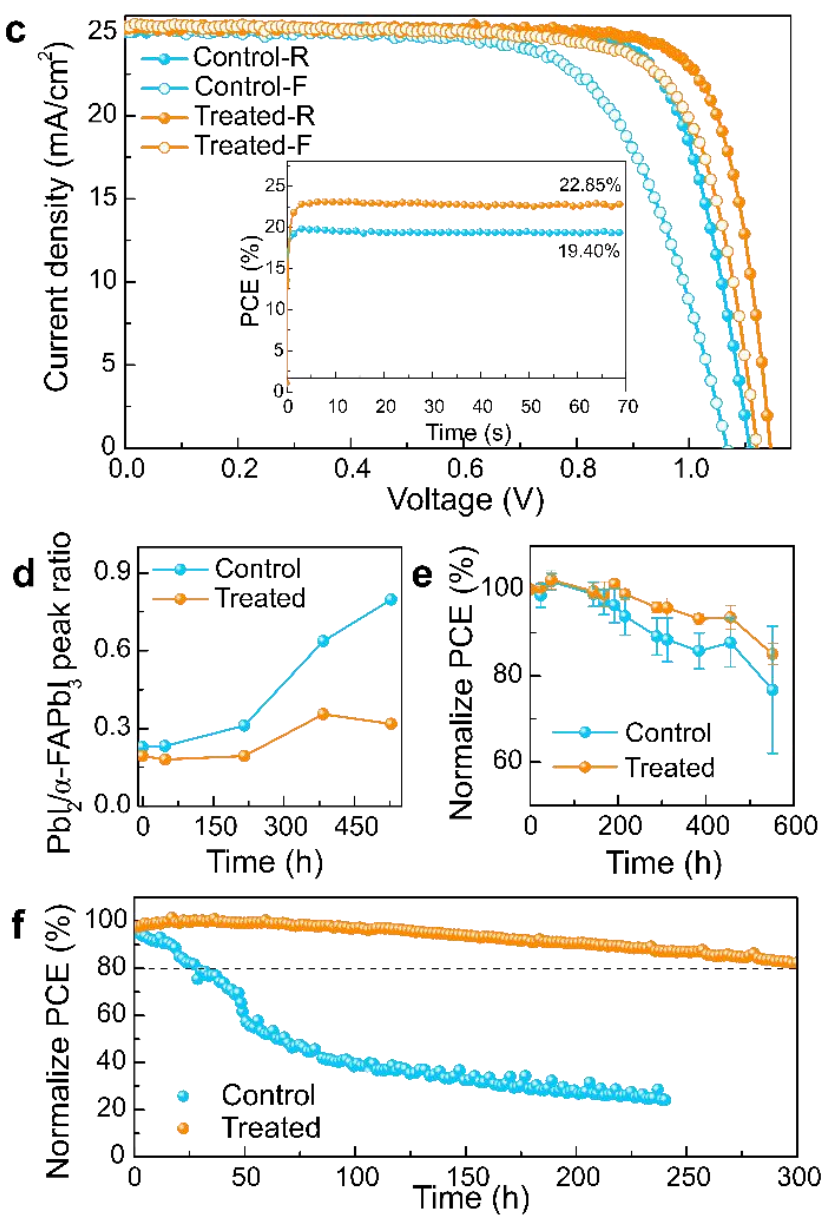

Figure 5. Device performance and stability. a, Cross-sectional SEM image of a typical crown ether treated PSC. The scale bar is $500 \mathrm{~nm}$. b, Photovoltaic metrics with and without treatment. c, $J-V$ curves of the champion PSC devices with and without treatment (antireflection film was used). The insert shows the maximum power point tracking data. $\mathbf{d}$, Plots of the ratio of the $\mathrm{PbI}_{2} 2 \theta=12.69^{\circ}$ and $\alpha-\mathrm{FAPbI}_{3}$ perovskite $2 \theta=13.97^{\circ} \mathrm{XRD}$ peaks for perovskite films stored in an ambient environment as a function of time. e, Ambient stability of PSCs based on the evolution of the average PCE change. The humidity and temperature were $60 \pm 10 \%$ and $25 \pm 1{ }^{\circ} \mathrm{C}$, respectively. f, Operational stability measured by maximum power point tracking under full solar illumination (AM $1.5 \mathrm{G}, 100 \mathrm{~mW} / \mathrm{cm}^{2}$ in $\mathrm{N}_{2}, 25^{\circ} \mathrm{C}$ ). $\mathrm{F}=$ Forward scan; $\mathrm{R}=$ Reverse scan.

Table 2. Summary of the photovoltaic parameters for the best control and crown ether modulated PSCs.

\begin{tabular}{|c|c|c|c|c|c|c|c|}
\hline Cell & $\begin{array}{c}\text { Scan } \\
\text { direction }\end{array}$ & $\begin{array}{l}V_{\mathrm{OC}} \\
(\mathrm{V})\end{array}$ & $\begin{array}{c}J_{\mathrm{SC}} \\
\left(\mathrm{mA} / \mathrm{cm}^{2}\right)\end{array}$ & $\mathrm{FF}$ & $\begin{array}{l}\text { PCE } \\
(\%)\end{array}$ & $\begin{array}{l}\text { Stabilized } \\
\text { PCE }(\%)\end{array}$ & $\begin{array}{l}\text { Hysteresis } \\
\text { index (HI) }\end{array}$ \\
\hline \multirow{2}{*}{ Control } & Reverse & 1.089 & 25.50 & 0.773 & 21.50 & \multirow{2}{*}{19.40} & \multirow{2}{*}{0.165} \\
\hline & Forward & 1.069 & 25.51 & 0.672 & 18.33 & & \\
\hline \multirow{2}{*}{$\begin{array}{c}\text { Crown ether } \\
\text { treated }\end{array}$} & Reverse & 1.154 & 25.80 & 0.795 & 23.70 & \multirow{2}{*}{22.85} & \multirow{2}{*}{0.05} \\
\hline & Forward & 1.122 & 25.73 & 0.753 & 21.74 & & \\
\hline
\end{tabular}




\section{Device physics and origin of the performance improvement}

Because the crown ether treatment suppresses surface defects enhancing nonradiative carrier recombination, it is expected to have an impact on the quasi-Fermi level splitting $\left(\Delta E_{F}\right)$ which represents the upper limit for the $V_{\mathrm{OC}}$. We investigated this by measuring absolute photoluminescence (PL) photon fluxes $\Phi_{P L}(E)$ of complete devices in an integrating sphere setup (Fig. 6a). From this, we could determine the photoluminescence quantum yield (PLQY), which was $0.12 \%$ for the control and $0.85 \%$ for the treated device. The PLQY was further used to calculate $\Delta E_{F}{ }^{35}$ :

$$
\Delta E_{F}=q V_{o c, r a d}+k_{B} T \ln (P L Q Y)
$$

where $q$ is the elementary charge, $V_{o c, r a d}$ is the radiative limit of $V_{o c}, k_{B}$ the Boltzmann constant and $\mathrm{T}$ $=25^{\circ} \mathrm{C}$ the sample temperature. $V_{o c, r a d}$ is calculated by the equation ${ }^{36}$ :

$$
V_{o c, r a d}=\frac{k_{B} T}{q} \ln \left(\frac{J_{s c}}{J_{\text {rad }, 0}}+1\right)
$$

Here, $J_{\mathrm{sc}}$ is the measured photocurrent, $J_{r a d, 0}=q \int_{0}^{\infty} a(E) \Phi_{B B}(E) d E$ the dark emission current and $\Phi_{B B}(E)=\frac{1}{4 \pi^{2} \hbar^{3} c^{2}} \frac{E^{2}}{\exp \left(E /\left(k_{B} T\right)\right)-1}$ the blackbody radiation. The absorptance $a(\mathrm{E})$ is derived from the PL spectra $\Phi_{P L}(E)$ (Fig. 6a) by applying the detailed balance principle $37-38: \Phi_{P L}(E) \propto a(E) \Phi_{B B}(E)$. Fig. $6 \mathrm{~b}, \mathrm{c}$ show the absorptance spectra and the PL and blackbody spectra from which they were derived. Since the sub-bandgap absorptance can be determined in this way with high precision, this also allows for the determination of the Urbach energy.

Table 3. Summary of the optoelectronic parameters for the control and crown ether treated device.

\begin{tabular}{ccc}
\hline & Control & Treated \\
\hline$V_{O C, \text { rad }}(\mathrm{V})$ & 1.266 & 1.277 \\
$\operatorname{PLQY}(\%)$ & 0.12 & 0.85 \\
$\Delta E_{F}(\mathrm{eV})$ & 1.093 & 1.155 \\
Measured $V_{O C}(\mathrm{~V})$ & 1.089 & 1.154 \\
\hline
\end{tabular}

In Table 3 we show the results of the $V_{o c \text {, rad }}$ calculation. The values are similar for the control and the treated films, the small difference being attributed to the statistical compositional batch-to-batch fluctuations. Table 3 also shows the comparison of the calculated $\Delta E_{F}$ with the measured $V_{\mathrm{OC}}$ of the same device. The two values are in excellent agreement, which confirms that the $V_{O C}$ improvement originates mainly from a $\Delta E_{F}$ increase, and thus from a reduction in non-radiative recombination.

The origin of the performance improvement is further analyzed in terms of the devices' diode characteristics. First, we evaluated the ideality factor $n$ by measuring the dependence of $V_{O C}$ on the incident light intensity (Fig. 6d). Upon surface treatment, the ideality factor decreases from 1.83 to 1.35 , indicative of suppressed non-radiative recombination channels ${ }^{39}$. Accordingly, we fit the $J-V$ curves of the champion control and treated devices to a single-diode equivalent circuit mode ${ }^{40}$ (Fig. S16 a-b and Table 
S3). Following the analysis proposed by Guillemoles et $a l .{ }^{41}$ and Stolterfoht et $a l .{ }^{42}$, the main loss mechanisms can be analyzed (Fig. 6e). First, the Shockley-Queisser limit is calculated from the bandgap which we determined from the inflection point of the EQE spectrum, as recommended by Krückemeier et al. ${ }^{43}$ (Fig. S16c-d). For the control device, we obtain a bandgap of $1.559 \mathrm{eV}$ and for the treated device, $1.564 \mathrm{eV}$, which are similar as expected. In the next step, the radiative limit $J-V$ curve is calculated using $V_{o c \text {, rad }}$ and the measured $J_{\mathrm{sc}}$ of the champion cells, again assuming an ideal diode behavior $(n=1$, with series and shunt resistances of $R_{\mathrm{S}}=0$ and $R_{\mathrm{sh}}=\infty$, respectively). The performance losses related to the radiative limit with respect to the Shockley-Queisser limit account for $1.6 \%\left(V_{\mathrm{oc}} \operatorname{loss}\right)+5.2 \%\left(J_{\mathrm{sc}} \operatorname{loss}\right)=$ $6.8 \%$ for the control and $1.1 \%\left(V_{\mathrm{oc}} \mathrm{loss}\right)+3.6 \%\left(J_{\mathrm{sc}} \mathrm{loss}\right)=4.7 \%$ for the treated film, mainly stemming from $J_{\mathrm{SC}}$ losses due to non-ideal absorption. The contribution of non-radiative recombination in the bulk, at grain boundaries and at the interfaces is further evaluated by calculating a $J-V$ curve using the measured $J_{\mathrm{SC}}, V_{O C}$, and ideality factor while maintaining ideal resistances. Since this $J-V$ curve does not take into account any losses stemming from non-ideal charge transport it is called the transport limit. Note that this transport limit is similar to the pseudo $J-V$ curve obtained from the $J_{\mathrm{SC}}-V_{\mathrm{OC}}$ method introduced by Wolf and Rauschenbach ${ }^{44}$ to evaluate the series resistance of solar cells. Consistent with the previous findings, a significant improvement in non-radiative losses is observed, decreasing from $14.0 \%\left(\mathrm{~V}_{\mathrm{oc}} \mathrm{loss}\right)+8.3 \%$ ( $\mathrm{FF}$ loss $)=22.3 \%$ in the control device to $9.6 \%\left(\mathrm{~V}_{\mathrm{oc}}\right.$ loss $)+3.9 \%$ (FF loss $)=13.5 \%$ in the treated device. This shows that solar cell performance losses by non-radiative recombination are reduced by $40 \%$, confirming the role of the reduction of non-radiative recombination as the main driver for performance improvement in our study. Thereafter, the losses due to charge transport characterized by non-ideal series and shunt resistances and a further increased ideality factor are obtained from the measured $J-V$ curve. Transport losses manifest themself in a further reduction of FF. The transport-related FF losses of the control and treated samples are $6.6 \%$ and $8.4 \%$, respectively. Interestingly, the crown ether treatment did slightly impair charge transport which suggests that the DB24C8 complex creates a charge transport (hole transfer) barrier between the perovskite and the HTL. 

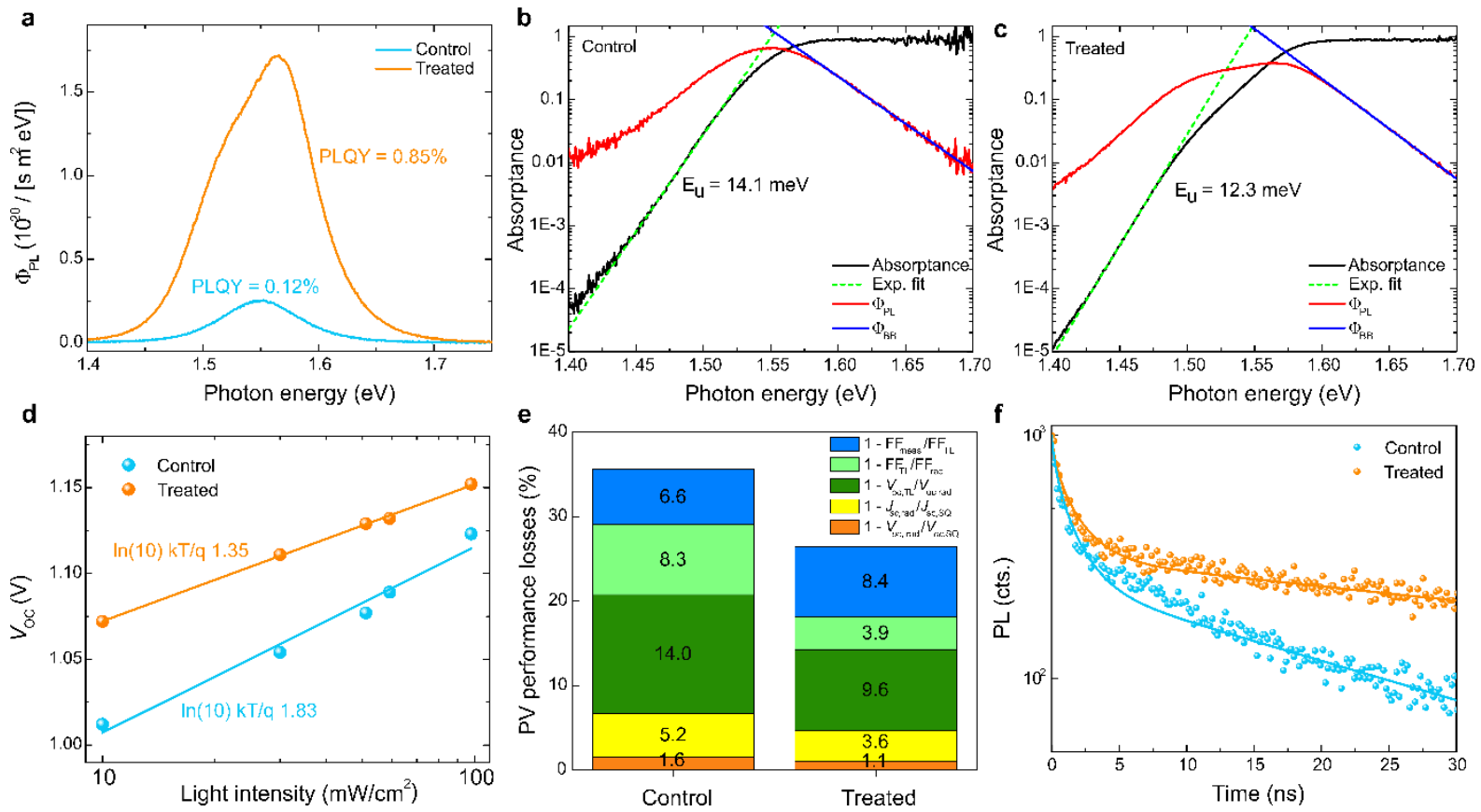

Figure 6. Opto-electronic characterization. a, Absolute photon flux $\Phi_{P L}(E)$ measurements of complete devices at 1-sun excitation from which the PLQY is determined. b, c, Absorptance determined from $\Phi_{P L}$ and $\Phi_{B B}$ as described in the main text for the control and the treated samples. $E_{u}$ is the Urbach energy derived from the slope of the exponential fit of the sub-bandgap absorptance. d, Light intensity dependence of $V_{o c}$. The ideality factor $n_{i d}$ is calculated from the slope of the linear fit of the semi-logarithmic plot. e, Photovoltaic performance losses due to non-ideal absorption (yellow), non-radiative recombination (dark and light green) and charge transport (blue). f, TRPL measurements of control and treated samples. The layer architecture is FTO glass/c- $\mathrm{TiO}_{2} / \mathrm{mp}^{-\mathrm{TiO}_{2} / \text { perovskite }}{ }^{45} /$ spiro-MeOTAD. The solid lines are fit curves according to the model described in the main text. For the latter, an absorption coefficient of $1 \cdot 10^{5} \mathrm{~cm}^{-1}$ at the laser excitation wavelength $(510 \mathrm{~nm})$ and an effective perovskite thickness of $640 \mathrm{~nm}\left(L_{\text {dense film }}+0.5 * L_{\text {meso-porous film }}\right)$ were used.

This loss in transport can also be seen in time-resolved PL measurements on treated and untreated perovskite films with HTL as shown in Fig. 6f. To simulate this data, we used a model based on the continuity equation for the carrier concentration $n(\mathrm{z}, \mathrm{t}): \frac{\partial n}{\partial t}=D \frac{\partial^{2} n}{\partial z^{2}}-k_{1} n-k_{2} n^{2}-k_{3} n^{3}$, where $D$ is the carrier diffusion coefficient, $k_{1}$ the non-radiative monomolecular bulk recombination constant, $k_{2}$ the radiative bimolecular recombination constant, and $k_{3}$ the Auger coefficient. We use low fluences $(<4.6$ $\mathrm{nJ} / \mathrm{cm}^{2}$ ) and from our simulations using $k_{2}=6 \times 10^{-11} \mathrm{~cm}^{3} / \mathrm{s}$ and $k_{3}=10^{-28} \mathrm{~cm}^{6} / \mathrm{s}$ we find that bimolecular and Auger recombination can be neglected in the continuity equation. ${ }^{38}$ We apply the boundary condition $J\left(z_{b}, t\right)=-D \frac{\partial n\left(z_{b}, t\right)}{\partial z}=\mathrm{S} \cdot n\left(z_{b}, t\right)$, where $z_{b}$ is the coordinate of the perovskite/HTM interface. This is usually used to account for surface recombinations, however, in our case the surface recombination velocity $\mathrm{S}$ can be interpreted as the hole transfer velocity between the perovskite 
and $\mathrm{HTL}^{46}$. S can also contain contributions from interface recombination, however, in our previous work we could show that for a time scale $<50 \mathrm{~ns}$ it is dominated by charge transfer. ${ }^{47}$ The PL signal is then obtained by $I_{P L}=\int_{0}^{L} k_{2} n(z, t)^{2} d z$, where $L$ is the film thickness. For the numerical simulation, we used the Crank-Nicolson method. Note that our model is a simplification of the real situation. It assumes, e.g. that the electron and hole concentration is equal throughout the film and at any time so that drift currents can be neglected. This is not always the case, in particular when hole transfer in the HTM is investigated. Further, the model assumes that bulk recombination can be described by a single recombination constant $k_{l}$ which is a simplification of the SRH model ${ }^{38}$. Nevertheless, the strength of this model is that it successfully explains qualitative trends while using only few fit parameters.

Two regimes in Fig $6 \mathrm{f}$ can be distinguished: a fast decay within the first $5 \mathrm{~ns}$ followed by a significantly slower monoexponential decay. From the simulations, we find that the fast decay is dominated by carrier diffusion which leads to a fast equilibration of the initially narrow exponential carrier concentration profile. The slower decay is mainly due to hole injection into the HTL. We also find that $\mathrm{k}_{1}$ - with an upper limit of $10^{6} \mathrm{~s}^{-1}$ as determined from time-resolved photoluminescence (TRPL) measurements without HTL (see Fig. S17 ${ }^{43}$ - has a negligible effect on the TRPL traces of the samples with the interface perovskite/HTL. For the best fits, we obtained a carrier mobility of $\mu=\frac{q}{k T} D=4 \mathrm{~cm}^{2} / \mathrm{Vs}$, which is in good agreement with literature, ${ }^{32,48}$ and a hole transfer velocity for the control and treated samples of $S_{\text {control }}=1500 \mathrm{~cm} / \mathrm{s}$ and $S_{\text {treated }}=400 \mathrm{~cm} / \mathrm{s}$ respectively. The more than 3 times lower hole transfer velocity of the treated film indicates an impaired charge transport through the perovskite/HTL interface which is in good agreement with the observed FF losses discussed above. Note that the FF losses referred to here are with respect to the respective transport limits. Overall, due to the improvement in non-radiative recombination losses, the FF of the treated device is higher than the one of the control device.

\section{Conclusions}

In summary, we report a host-guest strategy to modulate perovskite films, affording passivation of undercoordinated surface metal or organic cation defects via crown ether complexation. This interaction has been elucidated by solid-state NMR, ATR-FTIR, XPS as well as DFT calculations. The crown ether surface modulation reduces the trap state density at the absorber/hole transporting material interface, thus greatly suppressing solar cell performance losses due to non-radiative recombination by $40 \%$ as quantitatively determined by a concerted evaluation of PL, PLQY, and device performance measurements. As a result, the crown ether modulated PSCs exhibit improved operational stability and power conversion efficiency exceeding 23\%. Despite this performance improvement, the crown ether treatment creates a charge transport barrier between the perovskite and the HTL as analyzed by TRPL measurements which leaves room for further performance advancements of this interface through improved material design. Consequently, this work opens a new avenue to enhance the performance and stability of perovskite-based optoelectronic devices via supramolecular chemistry. 


\section{EXPERIMENTAL SECTION}

Fabrication of perovskite solar cell

Fluoride-doped tin oxide glass substrates (FTO, $4.0 \mathrm{~mm}$-thick, $10 \Omega / \mathrm{sq}$, Nippon Sheet Glass) were patterned using zinc powder and concentrated hydrochloric acid $(1 \mathrm{M})$. The patterned FTO was sequentially cleaned by 2 $\%$ commercial detergent (Hellmanex) water solution, deionized water, ethanol and acetone in ultrasonic bath for $15 \mathrm{~min}$, rinsed with deionized water and then dried by air blowgun. After $\mathrm{O}_{3} /$ ultraviolet treatment for $15 \mathrm{~min}$, the 20-40 nm compact layer $\mathrm{TiO}_{2}\left(\mathrm{c}-\mathrm{TiO}_{2}\right)$ was deposited on a cleaned FTO substrate by spray pyrolysis at $450{ }^{\circ} \mathrm{C}$ using a precursor solution of titanium diisopropoxide bis(acetylacetonate) with oxygen as the carrier gas. The precursor solution was prepared by taking $75 \mathrm{wt} . \%$ diisopropoxide bis(acetylacetonate) in isopropanol, diluting with ethanol with a volume ratio of 1:9, and addition of 4 vol\% acetylacetone. After cooling down to room temperature and $\mathrm{O}_{3} /$ ultraviolet treatment for $15 \mathrm{~min}$, the mesoporous $\mathrm{TiO}_{2}\left(\mathrm{mp}-\mathrm{TiO}_{2}\right)$ was spin-coated at 4000 rpm for $20 \mathrm{~s}$ onto the $\mathrm{c}-\mathrm{TiO}_{2}$ using a commercial paste (Dyesol 30 NR-D) diluted in ethanol (1:6, weight ratio) to achieve 100 to $150 \mathrm{~nm}$ thickness. After drying at $80{ }^{\circ} \mathrm{C}$ for $10 \mathrm{~min}$, the $\mathrm{TiO}_{2}$ films were gradually sintered to $450{ }^{\circ} \mathrm{C}$, kept at this temperature for $30 \mathrm{~min}$ and cooled to room temperature. Before use, the films were treated with $0.1 \mathrm{M}$ solution of Li-TFSI in acetonitrile by spin coating at $3000 \mathrm{rpm}$ for $20 \mathrm{~s}$ and then were sintered at 450 ${ }^{\circ} \mathrm{C}$ for $30 \mathrm{~min}$. After cooling down to $150{ }^{\circ} \mathrm{C}$, the substrates were transferred to dry-air glovebox (relative humidity $<15 \%$ ) for deposition of perovskite films. The perovskite film was deposited onto the $\mathrm{mp}-\mathrm{TiO}_{2}$ substrate from a precursor solution containing lead iodide (1.51 M, Alfa Aesar), formamidinium iodide (1.47 M, Greatcell), and methylammonium bromide (0.03 M, Greatcell), lead bromide (0.03 M, TCI) and methylammonium chloride $(0.6 \mathrm{M}$, Sigma-Aldrich) in anhydrous dimethylformamide (Acros)/ dimethylsulphoxide (Acros) (4:1 (v:v)) solution. The precursor solution was spin-coated in a two-step process at $1000 \mathrm{rpm}$ for $10 \mathrm{~s}$ and $6000 \mathrm{rpm}$ for $25 \mathrm{~s}$, respectively. During the second step, 200-300 $\mu 1$ of chlorobenzene (Acros) was dropped on the spinning substrate $10 \mathrm{~s}$ prior to the end of the process. The substrates were sequentially heated at $150{ }^{\circ} \mathrm{C}$ for $10 \mathrm{~min}$ for perovskite crystal formation.

For crown ether treatment, the different crown ethers in chlorobenzene with various concentrations were dynamic spin coated on to the as-formed perovskite films at $4000 \mathrm{rpm}$ for $20 \mathrm{~s}$. The treated perovskite films were heated at $100^{\circ} \mathrm{C}$ for $5 \mathrm{~min}$.

A hole transport material solution containing $75 \mathrm{mM}$ spiro-OMeTAD $(>99.5 \%$, Xi'an Polymer Light Technology Corp.) in chlorobenzene with 40 mM Li-TFSI (99.95\%, Sigma-Aldrich) and $270 \mathrm{mM}$ tBP (96\%, Sigma-Aldrich) additives was dynamic spin-coated onto the substrate at $3000 \mathrm{rpm}$ for $30 \mathrm{~s}$. The device fabrication is completed with deposition of a gold electrode $(\sim 70 \mathrm{~nm})$ by thermal evaporation.

\section{Characterization and measurement}

Surface morphologies and potential of perovskite films were examined by a SEM (Zeiss Merlin) and an AFM/KPFM (Cypher, Asylum Research). The UV-Vis absorption spectra of perovskite coated FTO glasses were measured by a UV-vis spectrophotometer (Varian Carry 500 spectrometer, USA). GIWAXS measurements were performed at the 12-ID-D beamline of the Advanced Photon Source at the Argonne National Laboratory (Lemont, USA). XPS and UPS (AXIS Supra, Kratos Analytical Ltd, UK) with a He-I source $(h v=21.22 \mathrm{eV})$ are used to probe the surface properties of perovskite film with and without crown ether treatment. The prepared 
perovskite solar cells were measured using a $300 \mathrm{~W}$ Xenon light source from Oriel. The spectral mismatch between AM 1.5G and the solar simulator was calibrated by a Schott K113 Tempax filter (Prazosopms G; as \& Optik $\mathrm{GmbH}$ ). A silicon photodiode was used as the light intensity calibrator for each measurement. A Keithley 2400 is used for the current-voltage scan by applying an external voltage bias and measuring the response current with a scan rate of $50 \mathrm{mV} / \mathrm{s}$. An anti-reflection coating was used for the champion devices. The device area was $0.25 \mathrm{~cm}^{2}(0.5 \mathrm{~cm} \times 0.5 \mathrm{~cm})$. The cells were masked with a black metal mask with an area of $0.16 \mathrm{~cm}^{2}$. External quantum efficiency (EQE) spectra were recorded with a commercial apparatus (Arkeo-Ariadne, Cicci Research s.r.l.) based on a $300 \mathrm{~W}$ Xenon lamp. The operational stability of the cells was measured under a white light-emitting diode lamp with biologic MPG2 potentiostat and was performed under a continuous nitrogen flow at $25{ }^{\circ} \mathrm{C}$. The device area is masked to around $0.13 \mathrm{~cm}^{2}$. The light intensity is around $100 \mathrm{~mW} \mathrm{~cm}-2$, and the actual current is adjusted according to in-time calibration results from the silicon diode. Photoluminescence quantum yield (PLQY) was measured using an integrating sphere (Fluorolog, Horiba JobinYvon), an Andor Kymera 193i spectrograph and a $660 \mathrm{~nm}$ continuous-wave laser (OBIS, Coherent) set at 1-Sun equivalent photon flux $(1.1 \mu \mathrm{m}$ beam full-width half-maximum, $632 \mu \mathrm{W})$; photoluminescence was collected at normal incidence using a $0.1 \mathrm{NA}, 110 \mu \mathrm{m}$-diameter optical fiber. For the calibration of the PLQY measurements we used a halogen lamp (HL-3 plus CAL from Ocean Optics), to check the correctness of the calibration we measured PLQY of a dye solution of indocyanine green in DMSO in the same setup and measured PLQY values within $15 \%$ deviation from the literature values. The photoluminescence lifetime was measured via time-correlated single photon counting (TCSPC) using a LifeSpec II (Edinburgh Instruments) fluorescence spectrometer with a picosecond pulsed diode laser (EPL-510, Edinburgh Instruments) at $510 \mathrm{~nm}$ wavelength and 85 ps pulse width. Solid-state NMR measurements were performed at $11.7 \mathrm{~T}$ with a Bruker Avance III spectrometer. ${ }^{1} \mathrm{H} \rightarrow{ }^{13} \mathrm{C} \mathrm{CP}$ and direct ${ }^{207} \mathrm{~Pb}$ experiments were performed at $15 \mathrm{kHz}$ magic angle spinning (MAS) with a low temperature $3.2 \mathrm{~mm}$ probe, while direct ${ }^{1} \mathrm{H},{ }^{1} \mathrm{H}-{ }^{1} \mathrm{H}$ spin diffusion, and ${ }^{207} \mathrm{~Pb} \rightarrow{ }^{1} \mathrm{H}$ and ${ }^{1} \mathrm{H} \rightarrow{ }^{13} \mathrm{C}$ HETCOR experiments were performed with a low temperature $1.3 \mathrm{~mm}$ probe. ${ }^{1} \mathrm{H} \rightarrow{ }^{13} \mathrm{C} \mathrm{CP}$ experiments used a contact time of $2 \mathrm{~ms}$ with rf powers of $\sim 55$ and $\sim 70 \mathrm{kHz}$ for ${ }^{1} \mathrm{H}$ and ${ }^{13} \mathrm{C}$, respectively, and recycle delays between 5 and $10 \mathrm{~s}$. Echo-detected ${ }^{207} \mathrm{~Pb} \rightarrow{ }^{1} \mathrm{H}$ HETCOR experiments used $30 \mathrm{kHz}$ MAS, a contact time of $6 \mathrm{~ms}$ with rf powers of $\sim 120$ and $\sim 150 \mathrm{kHz}$ for ${ }^{207} \mathrm{~Pb}$ and ${ }^{1} \mathrm{H}$, respectively, and an effective recycle delay of $80 \mathrm{~ms}$. Echo detected ${ }^{1} \mathrm{H}-{ }^{1} \mathrm{H}$ spin diffusion experiments used $40 \mathrm{kHz}$ MAS and a recycle delay of $1 \mathrm{~s}$. The ${ }^{207} \mathrm{~Pb} \rightarrow{ }^{1} \mathrm{H}$ HETCOR and $\delta-\mathrm{FAPbI}_{3}$ direct ${ }^{207} \mathrm{~Pb}$ spectra were measured at $113 \mathrm{~K}$, all other experiments were performed at room temperature. ${ }^{1} \mathrm{H}$ and ${ }^{13} \mathrm{C}$ experiments were referenced to adamantane at $1.91 \mathrm{ppm}$ and $38.5 \mathrm{ppm}$, respectively, and ${ }^{207} \mathrm{~Pb}$ experiments were referenced to $\mathrm{Pb}\left(\mathrm{NO}_{3}\right)_{2}$ at $-3492 \mathrm{ppm}$ at room temperature. Powder XRD patterns of the mechnosynthesised samples were recorded with a Bruker D8 Discover Vario diffractometer with a $\mathrm{Cu} \mathrm{K} \alpha_{1}$ monochromater $(1.540598 \AA)$ from $2 \theta=2-50^{\circ}$.

\section{Computational methods}

To calculate the crown-ether molecule complexation energies, DFT was employed using the Perdew-BurkeErnzerhof (PBE) functional ${ }^{49}$ within the CPMD package ${ }^{50}$. Valence-core electron interactions were modeled via norm-conserving pseudo-potentials in a simulation box of 50x50x50 $\AA^{3}$ together with a 100 Ry kinetic energy cutoff. DFT-optimized slabs were generated by $2 \times 2 \times 4$ replication of the cubic $\mathrm{FAPbI}_{3}$ unit cell. A k-point grid of 
$2 \times 2 \times 1(4 \times 4 \times 1$ for post processing analyses), the ultra-soft pseudo-potentials for valence-core electron interactions and the PBEsol functional ${ }^{51}$, with a plane wave basis set of 60 and 420 Ry cutoff values for the kinetic energy and the density were employed to conduct geometry optimization using the Quantum Espresso suite of $\operatorname{codes}^{52}$. A vacuum gap of $25 \AA$ was used to prevent interaction of the slab images. To make a rational comparison between the valence band maximum (VBM) and the conduction band minimum (CBM) of the different slabs, the energy levels were aligned proportionate to the energy levels of the $5 d$ orbitals of the $\mathrm{Pb}$ atoms in pristine $\mathrm{FAPbI}_{3}$. Crown-slab binding energies were calculated by subtracting the sum of the energies of the pristine slab and the crown from the modulated pristine slab. Crown-slab binding energies were calculated by subtracting the energy of the modulated pristine slab from the sum of the energies of the pristine untreated slab and the crown from the modulated pristine slab.

\section{AUTHOR INFORMATION}

\section{Corresponding Author}

* hong.zhang@epfl.ch (H.Z.); michael.graetzel@epfl.ch (M.G.)

\section{Author Contributions}

"These authors contribute equally to this work.

Notes.

The authors declare no competing financial interest. M.M. is also affiliated with the Scientific Computing Laboratory, Center for the Study of Complex Systems, Institute of Physics Belgrade, University of Belgrade, Pregrevica 118, 11080 Belgrade, Serbia. H.H.H. is also affiliated with the Center for Condensed Matter Sciences, Department of Materials Science and Engineering, National Taiwan University, Taipei 10617, Taiwan.

\section{ACKNOWLEDGMENTS}

This project has received funding from the European Union's Horizon 2020 research and innovation program GRAPHENE Flagship Core 3 grant agreement No.:881603 as well as Espresso under the agreement No.: 764047. U.R. acknowledges SNSF Grant No. 200020-185092, NCCR-MUST, and the SINERGIA interdisciplinary research program EPISODE for funding. This research used resources of the Advanced Photon Source, a U.S. Department of Energy (DOE) Office of Science User Facility operated for the DOE Office of Science by Argonne National Laboratory under Contract No. DE-AC02-06CH11357. L.E. is grateful for financial support from Swiss National Science Foundation Grant No. 200020-178860. O.O. acknowledges funding from the Natural Sciences and Engineering Research Council of Canada. T.S.S acknowledges funding from the Ministry of Science and Technology, Taiwan (MOST 108-2917-I-564-038 and 108-2221-E-007-102-MY3). J.L. and A.K. acknowledge funding from the European Union's Horizon 2020 Research and Innovation program under the Marie Skłodowska-Curie Grant Agreement No. 838686 and No. 843453, respectively. A.H. acknowledges the financial support from the Swiss National Science Foundation R'Equip program under the grant number 183305. H. H. H. acknowledges the financial support from 2019 New Partnership Program (108-2911-I-002-561). We also appreciate Dr. Jovana V. Milic for fruitful discussion. The authors acknowledge the help of Nicolas Tappy for the CL measurement.

\section{REFERENCES}


1. Quan, L. N.; Yuan, M.; Comin, R.; Voznyy, O.; Beauregard, E. M.; Hoogland, S.; Buin, A.; Kirmani, A. R.; Zhao, K.; Amassian, A.; Kim, D. H.; Sargent, E. H., Ligand-Stabilized Reduced-Dimensionality Perovskites. Journal of the American Chemical Society 2016, 138 (8), 2649-2655.

2. $\quad$ Lin, J.; Lai, M.; Dou, L.; Kley, C. S.; Chen, H.; Peng, F.; Sun, J.; Lu, D.; Hawks, S. A.; Xie, C.; Cui, F.; Alivisatos, A. P.; Limmer, D. T.; Yang, P., Thermochromic halide perovskite solar cells. Nature Materials 2018, $17(3), 261-267$.

3. Ogomi, Y.; Morita, A.; Tsukamoto, S.; Saitho, T.; Fujikawa, N.; Shen, Q.; Toyoda, T.; Yoshino, K.; Pandey, S. S.; Ma, T.; Hayase, S., $\mathrm{CH}_{3} \mathrm{NH}_{3} \mathrm{Sn}_{\mathrm{x}} \mathrm{Pb}_{(1-\mathrm{x})} \mathrm{I}_{3}$ Perovskite Solar Cells Covering up to $1060 \mathrm{~nm}$. The Journal of Physical Chemistry Letters 2014, 5 (6), 1004-1011.

4. Wang, F.; Bai, S.; Tress, W.; Hagfeldt, A.; Gao, F., Defects engineering for high-performance perovskite solar cells. npj Flexible Electronics 2018, 2 (1), 22.

5. Sum, T. C.; Mathews, N., Advancements in perovskite solar cells: photophysics behind the photovoltaics. Energy \& Environmental Science 2014, 7 (8), 2518-2534.

6. $\quad$ Li, B.; Zhang, Y.; Fu, L.; Yu, T.; Zhou, S.; Zhang, L.; Yin, L., Surface passivation engineering strategy to fully-inorganic cubic $\mathrm{CsPbI}_{3}$ perovskites for high-performance solar cells. Nature Communications 2018, 9 (1), 1076.

7. Bi, D.; Li, X.; Milić, J. V.; Kubicki, D. J.; Pellet, N.; Luo, J.; LaGrange, T.; Mettraux, P.; Emsley, L.; Zakeeruddin, S. M.; Grätzel, M., Multifunctional molecular modulators for perovskite solar cells with over $20 \%$ efficiency and high operational stability. Nature Communications 2018, 9 (1), 4482.

8. Azpiroz, J. M.; Mosconi, E.; Bisquert, J.; De Angelis, F., Defect migration in methylammonium lead iodide and its role in perovskite solar cell operation. Energy \& Environmental Science 2015, 8 (7), 2118-2127.

9. Braly, I. L.; deQuilettes, D. W.; Pazos-Outón, L. M.; Burke, S.; Ziffer, M. E.; Ginger, D. S.; Hillhouse, H. W., Hybrid perovskite films approaching the radiative limit with over $90 \%$ photoluminescence quantum efficiency. Nature Photonics 2018, 12 (6), 355-361.

10. Noel, N. K.; Abate, A.; Stranks, S. D.; Parrott, E. S.; Burlakov, V. M.; Goriely, A.; Snaith, H. J., Enhanced Photoluminescence and Solar Cell Performance via Lewis Base Passivation of Organic-Inorganic Lead Halide Perovskites. ACS Nano 2014, 8 (10), 9815-9821.

11. Zhang, H.; Nazeeruddin, M. K.; Choy, W. C. H., Perovskite Photovoltaics: The Significant Role of Ligands in Film Formation, Passivation, and Stability. Advanced Materials 2019, 31 (8), 1805702.

12. Ruiz-Preciado, M. A.; Kubicki, D. J.; Hofstetter, A.; McGovern, L.; Futscher, M. H.; Ummadisingu, A.; Gershoni-Poranne, R.; Zakeeruddin, S. M.; Ehrler, B.; Emsley, L.; Milić, J. V.; Grätzel, M., Supramolecular Modulation of Hybrid Perovskite Solar Cells via Bifunctional Halogen Bonding Revealed by Two-Dimensional 19F Solid-State NMR Spectroscopy. Journal of the American Chemical Society 2020, 142 (3), 1645-1654.

13. Qin, C.; Matsushima, T.; Fujihara, T.; Adachi, C., Multifunctional Benzoquinone Additive for Efficient and Stable Planar Perovskite Solar Cells. Advanced Materials 2017, 29 (4), 1603808.

14. Zhang, F.; Bi, D.; Pellet, N.; Xiao, C.; Li, Z.; Berry, J. J.; Zakeeruddin, S. M.; Zhu, K.; Grätzel, M., Suppressing defects through the synergistic effect of a Lewis base and a Lewis acid for highly efficient and stable perovskite solar cells. Energy \& Environmental Science 2018, 11 (12), 3480-3490. 
15. Jiang, Q.; Zhao, Y.; Zhang, X.; Yang, X.; Chen, Y.; Chu, Z.; Ye, Q.; Li, X.; Yin, Z.; You, J., Surface passivation of perovskite film for efficient solar cells. Nature Photonics 2019, 13 (7), 460-466.

16. Fan, L.; Ding, Y.; Luo, J.; Shi, B.; Yao, X.; Wei, C.; Zhang, D.; Wang, G.; Sheng, Y.; Chen, Y.; Hagfeldt, A.; Zhao, Y.; Zhang, X., Elucidating the role of chlorine in perovskite solar cells. Journal of Materials Chemistry A 2017, 5 (16), 7423-7432.

17. Zheng, X.; Chen, B.; Dai, J.; Fang, Y.; Bai, Y.; Lin, Y.; Wei, H.; Zeng, Xiao C.; Huang, J., Defect passivation in hybrid perovskite solar cells using quaternary ammonium halide anions and cations. Nature Energy 2017, 2 (7), 17102.

18. Sha, W. E. I.; Ren, X.; Chen, L.; Choy, W. C. H., The efficiency limit of $\mathrm{CH}_{3} \mathrm{NH}_{3} \mathrm{PbI}_{3}$ perovskite solar cells. Applied Physics Letters 2015, 106 (22), 221104.

19. Steed, J. W., First-and second-sphere coordination chemistry of alkali metal crown ether complexes. Coordination Chemistry Reviews 2001, 215 (1), 171-221.

20. Landini, D.; Maia, A.; Montanari, F.; Pirisi, F. M., Crown ethers as phase-transfer catalysts. A comparison of anionic activation in aqueous-organic two-phase systems and in low polarity anhydrous solutions by perhydrodibenzo-18-crown-6, lipophilic quaternary salts, and cryptands. Journal of the Chemical Society, Perkin Transactions 2 1980, (1), 46-51.

21. Vendilo, A. G.; Djigailo, D. I.; Smirnova, S. V.; Torocheshnikova, I. I.; Popov, K. I.; Krasovsky, V. G.; Pletnev, I. V., 18-Crown-6 and dibenzo-18-crown-6 assisted extraction of cesium from water into room temperature ionic liquids and its correlation with stability constants for cesium complexes. Molecules 2009, 14 (12), 5001-5016.

22. Chatterjee, T.; Sarma, M.; Das, S. K., Supramolecular architectures from ammonium-crown ether inclusion complexes in polyoxometalate association: synthesis, structure, and spectroscopy. Crystal growth \& design 2010, 10 (7), 3149-3163.

23. Prochowicz, D.; Saski, M.; Yadav, P.; Grätzel, M.; Lewiński, J., Mechanoperovskites for photovoltaic applications: preparation, characterization, and device fabrication. Accounts of Chemical Research 2019, 52 (11), 3233-3243.

24. Chen, Y.; Smock, S. R.; Flintgruber, A. H.; Perras, F. A.; Brutchey, R. L.; Rossini, A. J., Surface Termination of $\mathrm{CsPbBr} 3$ Perovskite Quantum Dots Determined by Solid-State NMR Spectroscopy. Journal of the American Chemical Society 2020, 142 (13), 6117-6127.

25. Franssen, W. M. J.; van Es, S. G. D.; Dervişoğlu, R.; de Wijs, G. A.; Kentgens, A. P. M., Symmetry, Dynamics, and Defects in Methylammonium Lead Halide Perovskites. The Journal of Physical Chemistry Letters 2017, 8 (1), 61-66.

26. Alharbi, E. A.; Alyamani, A. Y.; Kubicki, D. J.; Uhl, A. R.; Walder, B. J.; Alanazi, A. Q.; Luo, J.; Burgos-Caminal, A.; Albadri, A.; Albrithen, H.; Alotaibi, M. H.; Moser, J.-E.; Zakeeruddin, S. M.; Giordano, F.; Emsley, L.; Grätzel, M., Atomic-level passivation mechanism of ammonium salts enabling highly efficient perovskite solar cells. Nature Communications 2019, 10 (1), 3008.

27. Zhang, J.; Wang, Z.; Mishra, A.; Yu, M.; Shasti, M.; Tress, W.; Kubicki, D. J.; Avalos, C. E.; Lu, H.; Liu, Y.; Carlsen, B. I.; Agarwalla, A.; Wang, Z.; Xiang, W.; Emsley, L.; Zhang, Z.; Grätzel, M.; Guo, W.; Hagfeldt, A., 
Intermediate Phase Enhances Inorganic Perovskite and Metal Oxide Interface for Efficient Photovoltaics. Joule 2020, 4 (1), 222-234.

28. Kubicki, D. J.; Prochowicz, D.; Hofstetter, A.; Saski, M.; Yadav, P.; Bi, D.; Pellet, N.; Lewiński, J.; Zakeeruddin, S. M.; Grätzel, M.; Emsley, L., Formation of Stable Mixed Guanidinium-Methylammonium Phases with Exceptionally Long Carrier Lifetimes for High-Efficiency Lead Iodide-Based Perovskite Photovoltaics. Journal of the American Chemical Society 2018, 140 (9), 3345-3351.

29. Hanrahan, M. P.; Men, L.; Rosales, B. A.; Vela, J.; Rossini, A. J., Sensitivity-Enhanced 207Pb Solid-State NMR Spectroscopy for the Rapid, Non-Destructive Characterization of Organolead Halide Perovskites. Chemistry of Materials 2018, 30 (20), 7005-7015.

30. Aebli, M.; Piveteau, L.; Nazarenko, O.; Benin, B. M.; Krieg, F.; Verel, R.; Kovalenko, M. V., Lead-Halide Scalar Couplings in ${ }^{207} \mathrm{~Pb}$ NMR of $\mathrm{APbX}_{3}$ Perovskites $(\mathrm{A}=\mathrm{Cs}$, Methylammonium, Formamidinium; $\mathrm{X}=\mathrm{Cl}, \mathrm{Br}$, I). Scientific Reports 2020, 10 (1), 1-9.

31. Wang, R.; Xue, J.; Wang, K.-L.; Wang, Z.-K.; Luo, Y.; Fenning, D.; Xu, G.; Nuryyeva, S.; Huang, T.; Zhao, Y.; Yang, J. L.; Zhu, J.; Wang, M.; Tan, S.; Yavuz, I.; Houk, K. N.; Yang, Y., Constructive molecular configurations for surface-defect passivation of perovskite photovoltaics. Science 2019, 366 (6472), 1509-1513. 32. Sherkar, T. S.; Momblona, C.; Gil-Escrig, L.; Ávila, J.; Sessolo, M.; Bolink, H. J.; Koster, L. J. A., Recombination in Perovskite Solar Cells: Significance of Grain Boundaries, Interface Traps, and Defect Ions. ACS Energy Letters 2017, 2 (5), 1214-1222.

33. Li, W.; Rothmann, M. U.; Liu, A.; Wang, Z.; Zhang, Y.; Pascoe, A. R.; Lu, J.; Jiang, L.; Chen, Y.; Huang, F.; Peng, Y.; Bao, Q.; Etheridge, J.; Bach, U.; Cheng, Y.-B., Phase Segregation Enhanced Ion Movement in Efficient Inorganic CsPbIBr 2 Solar Cells. Advanced Energy Materials 2017, 7 (20), 1700946.

34. Kim, H.-S.; Park, N.-G., Parameters Affecting $I-V$ Hysteresis of $\mathrm{CH}_{3} \mathrm{NH}_{3} \mathrm{PbI}_{3}$ Perovskite Solar Cells: Effects of Perovskite Crystal Size and Mesoporous $\mathrm{TiO}_{2}$ Layer. The Journal of Physical Chemistry Letters 2014, 5 (17), 2927-2934.

35. Ross, R. T., Some Thermodynamics of Photochemical Systems. The Journal of Chemical Physics 1967, $46(12), 4590-4593$.

36. Rau, U., Reciprocity relation between photovoltaic quantum efficiency and electroluminescent emission of solar cells. Physical Review B 2007, 76 (8), 085303.

37. Wurfel, P., The chemical potential of radiation. Journal of Physics C: Solid State Physics 1982, 15 (18), 3967-3985.

38. Kirchartz, T.; Márquez, J. A.; Stolterfoht, M.; Unold, T., Photoluminescence-Based Characterization of Halide Perovskites for Photovoltaics. Advanced Energy Materials 2020, 1904134.

39. Tress, W.; Yavari, M.; Domanski, K.; Yadav, P.; Niesen, B.; Correa Baena, J. P.; Hagfeldt, A.; Graetzel, M., Interpretation and evolution of open-circuit voltage, recombination, ideality factor and subgap defect states during reversible light-soaking and irreversible degradation of perovskite solar cells. Energy \& Environmental Science 2018, 11 (1), 151-165.

40. Zhang, C.; Zhang, J.; Hao, Y.; Lin, Z.; Zhu, C., A simple and efficient solar cell parameter extraction method from a single current-voltage curve. Journal of Applied Physics 2011, 110 (6), 064504. 
41. Guillemoles, J.-F.; Kirchartz, T.; Cahen, D.; Rau, U., Guide for the perplexed to the Shockley-Queisser model for solar cells. Nature Photonics 2019, 13 (8), 501-505.

42. Stolterfoht, M.; Grischek, M.; Caprioglio, P.; Wolff, C. M.; Gutierrez-Partida, E.; Peña-Camargo, F.; Rothhardt, D.; Zhang, S.; Raoufi, M.; Wolansky, J.; Abdi-Jalebi, M.; Stranks, S. D.; Albrecht, S.; Kirchartz, T.; Neher, D., How To Quantify the Efficiency Potential of Neat Perovskite Films: Perovskite Semiconductors with an Implied Efficiency Exceeding 28\%. Advanced Materials 2020, 2000080.

43. Krückemeier, L.; Rau, U.; Stolterfoht, M.; Kirchartz, T., How to Report Record Open-Circuit Voltages in Lead-Halide Perovskite Solar Cells. Advanced Energy Materials 2020, 10 (1), 1902573.

44. Wolf, M.; Rauschenbach, H., Series resistance effects on solar cell measurements. Advanced energy conversion 1963, 3 (2), 455-479.

45. Milić, J. V.; Im, J.-H.; Kubicki, D. J.; Ummadisingu, A.; Seo, J.-Y.; Li, Y.; Ruiz-Preciado, M. A.; Dar, M. I.; Zakeeruddin, S. M.; Emsley, L.; Grätzel, M., Supramolecular Engineering for Formamidinium-Based Layered 2D Perovskite Solar Cells: Structural Complexity and Dynamics Revealed by Solid-State NMR Spectroscopy. Advanced Energy Materials 2019, 9 (20), 1900284.

46. Baloch, A. A. B.; Alharbi, F. H.; Grancini, G.; Hossain, M. I.; Nazeeruddin, M. K.; Tabet, N., Analysis of Photocarrier Dynamics at Interfaces in Perovskite Solar Cells by Time-Resolved Photoluminescence. The Journal of Physical Chemistry C 2018, 122 (47), 26805-26815.

47. Zhu, H.; Liu, Y.; Eickemeyer, F. T.; Pan, L.; Ren, D.; Ruiz-Preciado, M. A.; Carlsen, B.; Yang, B.; Dong, X.; Wang, Z.; Liu, H.; Wang, S.; Zakeeruddin, S. M.; Hagfeldt, A.; Dar, M. I.; Li, X.; Grätzel, M., Tailored Amphiphilic Molecular Mitigators for Stable Perovskite Solar Cells with 23.5\% Efficiency. Advanced Materials 2020, 32 (12), 1907757.

48. Wenger, B.; Nayak, P. K.; Wen, X.; Kesava, S. V.; Noel, N. K.; Snaith, H. J., Consolidation of the optoelectronic properties of $\mathrm{CH} 3 \mathrm{NH} 3 \mathrm{PbBr} 3$ perovskite single crystals. Nature Communications 2017, 8 (1), 590.

49. Perdew, J. P.; Burke, K.; Ernzerhof, M., Generalized Gradient Approximation Made Simple. Physical Review Letters 1996, 77 (18), 3865-3868.

50. CPMD, http://www.cpmd.org/ Copyright IBM Corp 1990-2015, Copyright MPI für Festkörperforschung Stuttgart 1997-2001.

51. Perdew, J. P.; Ruzsinszky, A.; Csonka, G. I.; Vydrov, O. A.; Scuseria, G. E.; Constantin, L. A.; Zhou, X.; Burke, K., Restoring the Density-Gradient Expansion for Exchange in Solids and Surfaces. Physical Review Letters 2008, 100 (13), 136406.

52. Giannozzi, P.; Baroni, S.; Bonini, N.; Calandra, M.; Car, R.; Cavazzoni, C.; Ceresoli, D.; Chiarotti, G. L.; Cococcioni, M.; Dabo, I.; Dal Corso, A.; de Gironcoli, S.; Fabris, S.; Fratesi, G.; Gebauer, R.; Gerstmann, U.; Gougoussis, C.; Kokalj, A.; Lazzeri, M.; Martin-Samos, L.; Marzari, N.; Mauri, F.; Mazzarello, R.; Paolini, S.; Pasquarello, A.; Paulatto, L.; Sbraccia, C.; Scandolo, S.; Sclauzero, G.; Seitsonen, A. P.; Smogunov, A.; Umari, P.; Wentzcovitch, R. M., QUANTUM ESPRESSO: a modular and open-source software project for quantum simulations of materials. Journal of Physics: Condensed Matter 2009, 21 (39), 395502. 